\title{
NUEVOS DEBERES PRECONTRACTUALES DE INFORMACIÓN EN LOS CERTIFICADOS DE COBERTURA PROVISORIO, DEFINITIVO Y LA PROPUESTA DEL CONTRATO DE SEGURO*
}

\section{MARCELO BARRIENTOS ZAMORANO**}

RESUMEN: En el contrato de seguro el deber precontractual de información y comportamiento de las partes cobra especial importancia en tres instrumentos, ausentes por cierto en otros contratos distintos al seguro, los certificados de cobertura o certificado definitivo y el certificado provisorio y la propuesta, creados por la ley 20.667. Explicaremos esta afirmación, ofreciendo una visión general del estudio de las fuentes normativas de los certificados de cobertura o certificado definitivo y el certificado provisorio y los modelos legislativos que fueron tenidos en cuenta por el congreso chileno en relación al deber precontractual de información.

PALABRAS CLAVE: Seguros - deber precontractual de información certificado de cobertura - propuesta.

\section{PRECONTRACTUAL NEW DUTIES OF INFORMATION IN TEMPORARY CERTIFICATES OF COVERAGE, AND FINAL PROPOSAL OF INSURANCE CONTRACT}

ABSTRACT: In the insurance contract the pre-contractual duty of disclosure and conduct of the parties is particularly important in three

\footnotetext{
* Este trabajo forma parte de la investigación que se realiza en el marco del Proyecto de Investigación: Fondecyt Regular $N^{\circ} 1141220$, titulado "El contrato de seguro como contrato de consumo. Examen critico de su estructura y sistematización después de las reformas de la ley de protección del consumidor y el Código de Comercio". Este artículo también forma parte del proyecto de investigación que recibe las "Ayuda a la Investigación 2012" de la Fundación Mapfre en el marco del proyecto "Formación del contrato de seguro en la nueva ley del consumidor chilena y su última modificación del 2011, ley 20.555". Por último, también forma parte del proyecto Anillo-CONICYT código SOC 1111. El autor desea expresar su agradecimiento a la colaboración prestada, en la investigación de las fuentes de este trabajo, a los ayudantes alumnos de la facultad de derecho de la Pontificia Universidad Católica de Chile: Ricardo Ihle, Claudia Villablanca y Adriana Villamizar.

Fecha de recepción: 30 de julio de 2014.

Fecha de aceptación: 28 de noviembre de 2014.

** Profesor de Derecho Civil de la Pontificia Universidad Católica de Chile [Chile]. Doctor en Derecho con mención "Doctor Europeus", Universidad de Salamanca [EspaÑa]. Magíster en Derecho de la Empresa, Pontificia Universidad Católica de Chile [CHILE]. Abogado. Correo electrónico: mhbz@uc.cl
} 
instruments, certificates of coverage or final certificate and provisory certificate and the proposal created by the law 20.667. It will be offered an overview of the study of the normative sources of certificates of coverage or final certificate and provisory certificate and legislative models that were considered by the Chilean Congress in relation to pre-contractual duty of disclosure.

KEY WORDS: Insurance - precontractual information duties - insurance certificate - proposal.

\section{INTRODUCCIÓN}

Fruto de la reforma al mercado asegurador chileno y como consecuencia de la publicación de la ley 20.667, de 9 de mayo de 2013, hay una nueva regulación del contrato de seguro en el Código de Comercio (en adelante CCOM), legislación que se une a la Ley 19.496, de protección de consumidores (en adelante, LPC) modificada a su vez por la ley $20.555^{1}$, que introduce nuevos derechos para los asegurados consumidores, y que considera a los seguros como productos financieros, a partir de diciembre de 2011.

Entendemos al nuevo contrato de seguro como uno consensual y de adhesión, en el que se vertebran deberes precontractuales de información imperativos gracias a la legislación misma que hoy rige el contrato de seguro.

Por la naturaleza especial del contrato de seguro, la formación del consentimiento en el mismo es muy distinta a aquella manifestada en los demás contratos del tráfico jurídico general, comercial y de consumo. Esto precisamente hace que reflexionemos en este artículo sobre los signos propios de un deber precontractual de información y comportamiento de las partes de cara a tres instrumentos, ausentes por cierto en otros contratos distintos al seguro, los certificados de cobertura o certificado definitivo y el certificado provisorio y la propuesta, creados por la ley 20.667. Estos instrumentos generan una reinterpretación, en el contrato de seguros, sobre las cargas y deberes propios de los deberes precontractuales. En efecto, el deber precontractual de información se expande a documentos en los que la misma creación del contrato de seguro se fragmenta. Es por ello que hay que configurar su contenido con cuidado y delinearlo en el nuevo contrato de seguro del CCOM chileno.

$1 \quad$ El Código de comercio chileno fue modificado mediante la Ley 20.667 publicada en el Diario Oficial (en adelante D.O) el 9 de mayo de 2013. La referida ley tuvo una vacancia legal. El artículo transitorio de esta ley, señalaba: "La presente ley comenzará a regir el primer día del séptimo mes siguiente al de su publicación”. La historia de la norma se encuentra disponible en: www.leychile.cl. [fecha de visita: 6 de julio de 2014]. 
Explicaremos esta afirmación, ofreciendo una visión general del estudio de las fuentes normativas de los certificados de cobertura o certificado definitivo y el certificado provisorio y los modelos legislativos que fueron tenidos en cuenta por el congreso chileno en relación al deber precontractual de información.

Nuestro artículo traza la exposición de estos extremos señalados de la siguiente forma:

1) Lugar que debieran ocupar en la formación del consentimiento del contrato de seguros los certificados de cobertura o certificado definitivo y el certificado provisorio.

1.1) El certificado provisorio en la formación del consentimiento del contrato de seguros y su relación con la propuesta.

1.2) El certificado definitivo en la formación del consentimiento del contrato de seguros y su relación con la propuesta.

1.3) Contenido del deber precontractual de información en la propuesta del seguro.

1.3.1) Los fundamentos del nuevo artículo 529 número 1 del Código de Comercio en relación al deber precontractual de asesoría durante la vigencia, modificación y renovación del contrato e incluso el siniestro.

1.3.2) Influencia de la ley de contratos de seguros alemana de 2008 en el deber precontractual de información y asesoría propio de los certificados de cobertura y la propuesta de seguro.

2) Normas administrativas modificadas recientemente sobre el deber de información al momento de celebración del contrato de seguros y la asesoría legal obligatoria.

3) La sanción de nulidad ante cláusulas de falta de información. Bases para una futura discusión.

1) LUGAR QUE DEBIERAN OCUPAR EN LA FORMACIÓN DEL CONSENTIMIENTO DEL CONTRATO DE SEGUROS LOS CERTIFICADOS DE COBERTURA O CERTIFICADO DEFINITIVO Y EL CERTIFICADO PROVISORIO

\section{1) EL CERTIFICADO PROVISORIO EN LA FORMACIÓN DEL CONSENTIMIENTO DEL CONTRATO DE SEGUROS Y SU RELACIÓN CON LA PROPUESTA}

El certificado provisorio está definido en la ley por el art. 513 e), según el cual "Para los efectos de la normativa sobre seguros se entenderá por: e) Certificado Provisorio: documento que da cuenta de los términos de un contrato de seguro cuya celebración está sujeta a la condición de que el asegurado cumpla con los requisitos estipulados, dentro de un pla- 
zo". El certificado provisorio es, en el tráfico jurídico de los seguros, un instrumento absolutamente independiente, temporal, que tiene, pese a su interinidad, rasgos que lo hacen de vital importancia en la formación del consentimiento de los seguros. Su destino primordial es estrictamente certificar, pero cabe la pregunta aquí sobre si este instrumento es una simple solicitud del seguro o ya es consentimiento propio del contrato de seguro. Y si es lo primero lo que concurre, solicitud de seguro, qué deberes deben respetarse en tal caso como irrenunciables para las partes habida cuenta del declarado sello imperativo de las normas del seguro en el CCOM.

Los certificados provisorios, tal y como señala Contreras: "son aquellos que emite informalmente la Compañía aseguradora, a petición del asegurado, con la sola finalidad de que este pueda cumplir con algún trámite legal relacionado con el transporte de importación o exportación de mercaderías, en particular con las prescripciones del Banco Central de Chile que exigen la cobertura del seguro para cursar registros de dicha especie"2.

En el tráfico diario, los certificados provisorios de cobertura, gracias a su carácter transitorio, tienen fecha de caducidad: la emisión de la póliza. No quiere decir ello que deban tenerse por independientes del contrato de seguro, más bien, operan como el documento antecedente del mismo, del que debe comprenderse como parte. En su vertiente precontractual, son evidencia de una realidad, tanto en el Common Law como en nuestro sistema romano-germánico, actualmente los contratos no se generan en un solo acto o secuencia lógica.

La técnica empleada por la ley al definir qué es un Certificado provisorio, tiene a nuestro juicio un propósito definido: generar seguridad jurídica en la contratación de los seguros. A nuestro entender, la pérdida del carácter solemne de este contrato, resta certezas a los momentos en los que los contratos de seguros se consienten, lo que no es necesariamente negativo, es un hecho del tráfico jurídico que hay que aceptar y llenar de contenido legal.

Las voluntades de tomador y el asegurador en el contrato de seguro, desde hace bastante tiempo, veían la escrituración un acto de mero formalismo "ad probationem, pero no como requisito ad substantiam", en palabras de Veiga Copo ${ }^{3}$. Los principios de prueba por escrito no son solo hoy los que permiten la posibilidad de fijar la existencia o no del contrato de seguro en sí mismo, sino que permiten precisar el sentido y alcance de las prestaciones de las partes en el vínculo jurídico formado, en los términos

\footnotetext{
2 Contreras Strauch, Osvaldo (2014) Derecho de Seguros, Segunda Edición, Editorial LegalPublishing, Thomson Reuters, Santiago de Chile, pp. 160, 760 pp.

3 Veiga Copo, Abel (2014) Tratado del Contrato de Seguro, Tomo I, Tercera Edición, Editorial Thomson Reuters, Civitas, Madrid, p. 139, 1542 pp.
} 
del artículo 515 del Código de Comercio, inciso segundo ${ }^{4}$. Por otro lado, especifican, el momento en que la etapa in contrahendo ha finalizado ${ }^{5}$.

Desde de la reforma de la ley 20.555, que extendió a los seguros las reglas propias de consumo a los seguros considerados como producto financiero, la autonomía privada no se puede manifestar en toda su independencia en los actos de consumo como la contratación de seguros que no sean de grandes riesgos. La libertad contractual ha quedado restringida, ya no podrá expresarse como la hace en el ámbito del Derecho civil o comercial, ello gracias al desequilibrio que se busca subsanar entre los proveedores de bienes y servicios financieros, como el seguro, y los consumidores y destinatarios finales o tomadores. Se debe ofrecer y garantizar en esta nueva lógica contractual, a un consumidor de seguros, transparencia todavía mayor en el marco de la prerrogativa propia de estos actos y, con ello, evitar actuaciones abusivas para con ellos. Ser un consumidor, y por cierto uno de seguros, no es solo tener la calidad de acreedor o deudor de una obligación de las definidas en el artículo 512 del Código de Comercio, es también propiamente consumir, en cuanto acto de consumo en sí mismo ${ }^{6}$.

Es hoy, por lo tanto, mayor la precariedad en la formación del consentimiento del seguro, lo que conlleva el peligro de la indeterminación y materialización de deberes precontractuales. El punto más sensible es que

4 Artículo 515 del Código de Comercio, inciso segundo: "La existencia y estipulaciones del contrato se podrán acreditar por todos los medios de prueba que contemplen las leyes, siempre que exista un principio de prueba por escrito que emane de cualquier documento que conste en télex, fax, mensajes de correo electrónico y, en general, cualquier sistema de transmisión y registro digital o electrónico de la palabra escrita o verbal".

5 Así en el derecho italiano, por ejemplo, en su obra de 1952 razonaba Valeri, pero que ya en 1908, cuarenta ańos antes, se había plasmado esta realidad en la hoy derogada antigua ley de seguros alemana de 1908. Valeri, Guiseppe (1950) Manuale di diritto commerciale. Tomo II, Firenze: Carlo Cya, p. 108, 241 pp. Por todos, Ríos Ossa, Roberto (2014) El deber precontractual de declaración de riesgo, Editorial Thomson Reuters La Ley, LegalPublishing, Santiago de Chile, pp. 11 y ss. 208 pp. En el derecho comparado y la práctica diaria, son muchos los aspectos que se ponen de relieve en la formación del consentimiento en un contrato de seguro, una de las principales y propia de este contrato es la de declarar el riesgo. Una obligación que actualmente es de cargo del asegurador como se ha puesto de relieve recientemente en nuestra doctrina por Ríos Ossa, pero que hace rato estaba ya clara en el derecho comparado.

$6 \quad$ Art. 512. Contrato de seguro. Por el contrato de seguro se transfieren al asegurador uno o más riesgos a cambio del pago de una prima, quedando este obligado a indemnizar el daño que sufriere el asegurado, o a satisfacer un capital, una renta $u$ otras prestaciones pactadas.

Los riesgos pueden referirse a bienes determinados, al derecho de exigir ciertas prestaciones, al patrimonio como un todo y a la vida, salud e integridad física o intelectual de un individuo. No solo la muerte sino que también la sobrevivencia constituyen riesgos susceptibles de ser amparados por el seguro. Las normas de este titulo rigen a la totalidad de los seguros privados. No son aplicables a los seguros sociales, a los contratos de salud regulados por el decreto con fuerza de ley $N^{\circ}$ 1, de 2006, del Ministerio de Salud, que fija el texto refundido, coordinado y sistematizado del decreto ley $N^{\circ} 2.763$, de 1979, y de las leyes $N^{\circ} 18.933$ y $N^{\circ} 18.469$, ni al seguro de accidentes del trabajo y enfermedades profesionales. 
elementos esenciales del mismo, como el riesgo cubierto, quede bajo una sombra de dudas por imprecisiones o vaguedades en su determinación. Recordemos que son requisitos esenciales del contrato de seguro, el riesgo asegurado, la estipulación de prima y la obligación condicional del asegurador de indemnizar, conforme al artículo 521 del Código de Comercio. La consecuencia de la falta de información suficiente sobre los citados elementos esenciales puede agudizar la clara asimetría de información, por parte especialmente del tomador, de los elementos esenciales que se deben siempre tener en cuenta para contratar un seguro. La consecuencia directa de ello es el empeoramiento de la calidad de la información que un contratante débil y predispuesto, en lo que a las cláusulas y su redacción se refiere, puede encontrar. En opinión de Contreras, esto es así porque "tampoco el certificado de cobertura provisorio otorga en realidad cobertura a riesgo alguno, real y efectivamente" 7 .

Por nuestra parte nos parece que, en el nuevo esquema del Código de Comercio, el certificado de cobertura provisorio sí otorga cobertura sobre el riesgo asegurado, como también con todas las cosas citadas en el artículo 521 del Código de Comercio: la estipulación de prima y la obligación condicional del asegurador de indemnizar. Lo anterior resulta indispensable para salvaguardar el vínculo que se crea entre tomador y asegurador, y para mantener los estándares de simetría entre las partes que el nuevo orden del contrato de seguro del Código de Comercio y la Ley de protección de consumidores miran como esencial. Creemos, por lo tanto, que en resguardo de lo que expresa el legislador, estamos en presencia de una carga de entregar este documento por parte de la aseguradora que le obliga a otorgar desde ya el riesgo asegurado, la estipulación de prima y la obligación condicional del asegurador de indemnizar, por lo que el Certificado provisorio, debiera estar en papel o en un soporte físico duradero que permita su prueba ${ }^{8}$.

Es indispensable que el Certificado provisorio se respete durante el iter contractual en su contenido por parte de la aseguradora, porque, tal

Contreras Strauch, Osvaldo (2014) Derecho de Seguros, Segunda Edición, Editorial LegalPublishing, Thomson Reuters, Santiago de Chile, pp. 160.

$8 \quad$ Corrobora lo anterior el mensaje de la ley 20.555, que modificó la ley de consumidores, en el que se declaraba: "las modificaciones específicas contenidas en este proyecto de ley, son las siguientes: 1. Mejorar las condiciones para que los consumidores puedan acceder a la información sobre los productos y servicios que se les ofrecen, principalmente mejorando los canales de información a través de Internet." Por su parte, en la tramitación de las mociones parlamentarias que dieron origen a la ley 20.667, que modificó el Título VIII del Libro II del Código de Comercio, se expresaba: "Este proyecto viene, así, a continuar el camino abierto por otras iniciativas legales recientes de gran importancia en materias propias del derecho comercial y económico, que ya se han materializado, como las modificaciones a la ley de protección al consumidor, a la ley de defensa de la libre competencia, la ley sobre arbitraje comercial internacional y la ley sobre la competencia desleal." La historia de la norma se encuentra disponible en: www.leychile.cl. [fecha de visita: 6 de julio 2014]. pp. 5. 
y como expresa Baraona para los actos de consumo en general, en ellos "[E]l contraste, por lo mismo, no se hace entre lo que se convino y lo que se recibió, sino entre lo que se ofreció por el proveedor y lo que efectivamente este entregó. Se introduce, así, un principio rector en el derecho del consumo, que es el principio de la transparencia del proveedor. Es una depuración cuya finalidad no busca dar garantía para el logro de un consentimiento libre, sino generar condiciones para un consumo libre y confiado"?

No se debe olvidar que el principio de transparencia, propio de los ámbitos de consumo, expresa una carga al proveedor que a partir de la ley 20.555, de 2011, se incorpora los artículos 17 A; 17 B; 17 C; 17 D; 17 G; 17 J y 17 L, señalando especiales deberes de información. Es por ello que el propio artículo 18 de la ley 19.496, expresa que son infracciones a las normas de la ley, el cobro de un precio superior al exhibido, informado o publicitado. Es más, conforme al propio artículo 17 de la referida ley, las aceptaciones deberán darse por escrito, expresamente, estampando la firma, para aquellos contratos que han de escriturarse. Esto supone una clara limitación a la libertad contractual que antes existió en el negocio de los seguros.

La ya conocida variante del deber de actuación de buena fe, el deber de información, unida al deber de cooperación y comportamiento leal de los contratantes, exigen la entrega de información al contratante más débil que, en razón de la circunstancia de estar frente a un contratante profesional, y que obra en virtud de sus especiales conocimientos del negocio, genera la confianza legítima en ella de ser correctamente informada por quien predispone el contrato de seguros ${ }^{10}$. Habrá de tenerse presente, en consecuencia, el artículo 16 de la ley 19.496, en cuanto a que se deberán evitar por el redactor de estos contratos aquellas cláusulas que objetivamente, creen un desequilibrio importante en los derechos y obligaciones de las partes, atendido el acuerdo sobre los elementos esenciales del mismo.

La principal consecuencia entonces, al extenderse por parte de la aseguradora el certificado de cobertura provisorio, es que queda singularizada a nuestro juicio la cobertura del contrato. El riesgo, gracias al certificado de cobertura provisorio emitido, ha sido desplazado desde el tomador al asegurador, lo que no significa que pueda luego complementarse o ampliarse consensualmente, lo contrario sería contemplar la posibilidad de desconocer un acto propio. Se obliga la aseguradora frente al tomador,

\footnotetext{
9 BARAONA, Jorge (2014) "La regulación contenida en la ley 19.496 sobre protección de los derechos de los consumidores y las reglas del código civil y comercial sobre contratos: un marco comparativo", Revista Chilena de Derecho, Vol. $41 \mathrm{~N}^{\circ} 2$, pp. 386.

10 Morales Moreno, Antonio Manuel (1988) El error en los contratos, editorial Ceura, Madrid, p. 299, 383 pp.
} 
por lo que no puede, en consecuencia, recusarse la cobertura extendida por parte de la misma, como tampoco podrá dispensar su responsabilidad si obvió la inspección del objeto cubierto por el seguro o no acometió su obligación de inspección en la forma que su lex artis imponía. Cobra especial relevancia su emisión ya que todo documento, examen o análisis que se pida para determinar el riesgo por parte de la aseguradora, irá complementado la formación definitiva del consentimiento. Se deriva de lo anterior, a nuestro juicio, que la cotización y la propuesta debieran estar en armonía con el consentimiento. ¿Por qué? Por la razón antes apuntada, no es lo que se acuerde lo más importante en el acto de consumo, lo que no quiere decir que no se pueda reclamar de ello también, sino lo que se ofreció por el proveedor de un seguro y finalmente se presta o cubre por este al asegurado.

En consecuencia, con la emisión del certificado provisorio se debieran cumplir los nuevos requisitos de deberes precontractuales de información que la nueva normativa de seguros chilena exige. Se busca un estándar de negociación justa, en relación al acto de consumo de creación de un seguro. La simetría de información exige que el asegurador transmita y requiera la información que se tiene sobre los riesgos que desea asegurar, la estipulación de prima y la obligación condicional del asegurador de indemnizar. Es también obligación del tomador facilitar y ayudar a la superación de la asimetría de información. Existe un deber de actuar con máxima buena fe, en definitiva, para ambas partes.

En abono de nuestra opinión, en el derecho comparado se arriba a similar conclusión. En efecto, el certificado provisorio chileno, recibe el nombre de "documento de cobertura provisorio" en el derecho español. A diferencia del régimen chileno, no tiene una definición en la Ley de Contrato de Seguros española. Se le entiende allí como un anticipo de la futura póliza, la que por razones de tiempo o físicas no pude ser, en el acto de formarse el consentimiento, aún emitida ${ }^{11}$. Tiene un extenso valor probatorio de la formación del consentimiento mismo, especialmente si recae en las cosas esenciales del contrato de seguro entre el tomador y la aseguradora, como lo es el riesgo ${ }^{12}$. Por su parte, la Ley belga de 25 junio

11 El contrato de seguro es consensual, si bien el artículo 5 de la LCS a efectos probatorios y también para que el tomador del seguro pueda conocer su normativa, impone al asegurador la obligación de entregar al tomador del seguro determinados documentos. Esta obligación del asegurador, impuesta por el artículo 5, de entregar la póliza o, al menos, el documento de cobertura provisorio nos descubre la consensualidad del contrato, nota que ha sido reconocida por la doctrina jurisprudencial Sánchez Calero, Fernando (2010) Ley de Contrato de Seguro, Aranzadi-Madrid, pp. 31 y 61, 2914 pp.

12 AAVV (2012), Todo Seguros, Coordinador D. Jorge Campos Moral, CISS grupo Wolters Kluwer, Madrid, pp. 192, 945 pp. Sobre el deber de protección de asegurado, el artículo 104 del Código del Mercado del Seguro expresa el "Deber general de información al tomador. 
1992, art. 4.2, tiene una reglamentación parecida y allí el Certificado de cobertura se lama "pólice présignée", entendiendo la doctrina y jurisprudencia belgas que el contrato de seguros es uno de adhesión y que este certificado de cobertura provisorio ya forma consentimiento sobre prestaciones esenciales de las partes.

En el derecho español, que parece ser antecedente de este certificado de cobertura provisorio, el mayor problema se ha presentado por el control de incorporación, que representa este momento de la formación del consentimiento en seguros, entre cláusulas limitativas y delimitadoras ${ }^{13}$. Como seńala un autor, "resulta especialmente conflictivo distinguir entre cláusulas limitativas y cláusulas delimitadoras del riesgo. Tampoco un estudio de la jurisprudencia permite extraer una línea interpretativa nítida. En ocasiones, ambos tipos se han equiparado, por lo que la calificación de cláusula limitativa o de cláusula delimitadora deviene intrascendente: ambas deberán ser destacadas y aceptadas expresamente. En una línea contraria se sostiene que, mientras delimitar consiste en acotar el riesgo objeto de cobertura y no requiere ulteriores requisitos, limitar consiste en excluir siniestros que usualmente quedan comprendidos dentro del mis-

1. Antes de celebrar un contrato de seguro distinto al seguro de vida, si el tomador es una persona física, o en cualquier contrato de seguro de vida, la entidad aseguradora deberá informar al tomador, por escrito, sobre los siguientes extremos:

a) Sobre la legislación aplicable al contrato cuando las partes no tengan libertad de elección o, en caso contrario, sobre la propuesta por el asegurador.

b) Sobre las diferentes instancias de reclamación, tanto internas como externas, utilizables en caso de litigio, así como el procedimiento a seguir.

2. Antes de la celebración de un contrato de seguro, distinto al contrato de seguro por grandes riesgos, la entidad aseguradora deberá informar al tomador, por escrito, del nombre del Estado miembro en el que esté establecido el domicilio social de la entidad con la que va a celebrar el contrato, la dirección de la entidad y, en el caso de operaciones en régimen de derecho de establecimiento, la dirección de la sucursal, así como la denominación social y la forma jurídica de la entidad.

3. Las informaciones mencionadas en los dos apartados anteriores deberán figurar en la póliza o en el documento de cobertura provisorio de forma clara y precisa.

La última versión de este Código en PDF y ePUB está disponible para su descarga gratuita en: www.boe.es/legislacion/codigos/ (fecha de visita 29 de mayo de 2014).

13 La Ley 30/1995, introdujo en el artículo 83 a) de la LCS, un derecho de resolución en el caso del contrato de seguro de vida. La redacción de este precepto ha sido modificada y ampliada posteriormente por la Ley 34/2003; de 4 de noviembre, en el sentido de conferir al tomador del seguro en un contrato de seguro sobre la vida, siempre que se tratara de un seguro individual superior a seis meses sobre la vida propia o de un tercero, la facultad unilateral de resolver el contrato sin indicación de los motivos y sin penalización alguna dentro del plazo de treinta días siguientes a la fecha en que el asegurador le entregue la póliza o el documento de Cobertura provisorio. Plazo que tiene un cómputo especial en el supuesto de que se hubiera concluido el contrato a distancia, ya que los treinta días habrían de contarse, en la fecha posterior a la conclusión del contrato y si es, con posterioridad a la perfección del contrato, cuando el tomador del seguro recibe las condiciones contractuales y toda la información. SánCHez Calero (2010) 31. 
mo y debe cumplirse" 14 . Como puede apreciarse, la discusión no es si estamos o no frente a un riesgo, sino más bien sobre su delimitación y ello es lo que puede cambiar con la póliza definitiva.

En esta misma línea se expresa esta idea en los "Principios de derecho europeo del contrato de seguros" o Draft Common Frame Of Reference Chapter III, Section IX, Insurance Contract, en los que la sección 4, Artículo 2:402, se refiere a la:

Cobertura preliminar

Cuando se concluya un contrato de seguro con cobertura preliminar, el asegurador deberá emitir una nota de cobertura que contendrá, si fuera relevante, la información especificada en el artículo 2:501 (a), (b), (d), (e) y (h).

Es decir:

Cuando se concluya un contrato de seguro, el asegurador deberá emitir una póliza de seguro, junto con las condiciones generales del contrato si estas no se encuentran incluidas en la póliza, conteniendo la siguiente información, si esta es relevante:

(a) el nombre y domicilio de las partes contratantes;

(b) el nombre y domicilio del asegurado y del beneficiario;

(d) el objeto del seguro y los riesgos cubiertos;

(e) la suma asegurada y sus deducciones;

(h) el período contractual y el período de responsabilidad ${ }^{15}$;

Si se advierte detenidamente en estos principios, a juicio de algún autor, en puridad no existe o no debe existir todavía contrato de seguro, sino más bien fases precontractuales del contrato de seguro que sin embargo ya contienen las cosas esenciales del mismo, como lo son el objeto del seguro y los riesgos cubiertos. Su principal efecto sería el de eximir temporalmente de la obligación de entregar toda la documentación propia del contrato y ayudar a advertir posibles inconsistencias del seguro. Se estaría aun negociando y es esta una cobertura provisoria y preliminar, ad cautelam, pero no por ello menos cobertura ${ }^{16}$.

Nos parece, habida cuenta de todo lo expresado hasta aquí, que se debe ir un punto más lejos en la protección del asegurado y que, en resguardo de los órdenes públicos de protección comprometidos a favor del contratante más débil, y en garantía de la interpretación in dubio pro asegurado se crea aquí una obligación del asegurador de incluir las condiciones generales en la proposición del seguro y que precisamente han de

\footnotetext{
14 Bataller, Juan, Latorre, Nuria y Olavarría, Jesús (2007) Derecho de los Seguros Privados, Editorial Marcial Pons-Madrid- España, pp.163, 391 pp.

15 Veiga Copo, Abel (2012) Los Principios de derecho europeo del contrato de seguros, Pontificia Universidad Javeriana de Colombia, Ibáñez, Colección prospectivas del Derecho $\mathrm{N}^{\circ}$ 2, pp. 138,504 pp.

16 Veiga Copo (2012) 139-141.
} 
estar señaladas en el certificado provisorio. En este sentido, es el asegurador el que debiera entregar al tomador las cláusulas de limitación de su cobertura del riesgo asegurado, la estipulación de prima y la obligación condicional del asegurador de indemnizar y este formar consentimiento, expreso e inequívoco, mediante su expresión de voluntad. El objetivo es que las informaciones que deba entregar el asegurador deben presentarse antes de la formación del consentimiento y uno de los medios por los que se prueba ésta es el Certificado provisorio.

No podemos olvidar que los contratos de seguros, considerados estos como productos financieros, tienen un especial énfasis de protección ${ }^{17}$. El Certificado de cobertura provisorio pertenece a una fase de formación del consentimiento en el seguro, por lo que todo el deber de información previo a la aceptación ya ha concluido, esto significa que necesariamente se deberá haber informado al tomador todo lo que manda la ley 19.496 y el Código de Comercio antes del perfeccionamiento del contrato de seguro, en aquellos seguros no exceptuados por el artículo 542 inciso segundo del Código de Comercio ${ }^{18}$. En efecto, la información básica comercial de la Ley de Protección del Consumidor, exige la entrega de "los datos, instructivos, antecedentes o indicaciones que el proveedor debe suministrar obligatoriamente al público consumidor, en cumplimiento de una norma jurídica”, conforme al artículo $1 \mathrm{~N}^{\circ} 3$. 3. Representa ella, junto al artículo 12 de la misma ley y 12 A, una clara limitación a la libertad contractual que las aseguradoras no pueden sino respetar ${ }^{19}$.

17 Ya desde el mensaje presidencial, se señalaba: "Por tanto, consideramos indispensables fortalecer la protección del consumidor de servicios financieros, de telecomunicaciones y de transporte público de pasajeros, entre otros, a través de la dotación de mayores atribuciones y competencias al referido Servicio Nacional del Consumidor, perfeccionando la entrega de información y realizando estudios que reduzcan las asimetrías de información. Estas atribuciones servirán también en otros mercados regulados de similares características al financiero." Ley publicada en el D.O el 5 de diciembre del 2011. La historia de la norma se encuentra disponible en: www.leychile.cl. [fecha de visita: 10 de marzo de 2013].

18 Siguiendo los modelos europeos tenidos en cuenta en la dictación de las normas chilenas de seguros, leyes 20.667 y 20.555, es importante tener en cuenta el "Final Report of the Comission Expert Group on European Insurance Law" que ha seńalado claramente que "la protección de los tomadores constituye un interés público superior”. Disponible en http://www. uibk.ac.at/zivilrecht/restatement/sprachfassungen/peicl-esp.pdf, (fecha de copnsulta 28 de julio de 2014). En el artículo 2:101 se señala:

Deber de información

(1) En el momento de concluir el contrato, el solicitante informará al asegurador de las circunstancias que el solicitante conozca o debería conocer, y que sean objeto de preguntas claras y precisas por parte del asegurador.

(2) Las circunstancias a las que hace referencia el párrafo 1 incluyen aquellas que la persona que sea asegurada conocía o debería haber conocido.

19 Es en el momento de emisión del certificado de cobertura provisorio que el uso de la tecnología ocupa hoy, además, un lugar central. El asegurador moderno hace uso de la técnica del "Big data", es decir, el uso de un conjunto masivo de datos que permite un mejor conocimiento del área de riesgo a cubrir y la posible materialización del siniestro. Este mecanismo 
Como puede apreciarse, el derecho de información actual en la formación del contrato de seguro exige todavía más intensidad que aquel propio de la formación del consentimiento en el Código de Comercio. Ha habido un cambio de paradigma, ya que en lo que a contratos de seguro se refiere, se ha pasado de un consentimiento libre y espontáneo, basado en la libertad contractual y la autonomía de la voluntad, la costumbre mercantil y las estipulaciones de las condiciones generales de las pólizas de seguro, a un auténtico consentimiento informado, que tiene como objetivo, entre otros, la tutela de los deberes precontractuales de información.

\section{2) EL CERTIFICADO DEFINITIVO EN LA FORMACIÓN DEL CONSENTIMIENTO DEL CONTRATO DE SEGUROS Y SU RELACIÓN CON LA PROPUESTA}

El certificado de cobertura o certificado definitivo está definido en el art. $513 \mathrm{~d}$ ), como el "documento que da cuenta de un seguro emitido con sujeción a los términos de una póliza de seguro colectivo o flotante”. Las pólizas de seguro flotante son propias del seguro de transporte marítimo. Su rasgo contractual queda ratificado por el inciso final del art. 515 del Código de Comercio que señala que: "Cuando el seguro conste de un certificado de cobertura definitivo, se entenderá que forman parte de este los términos y condiciones de la respectiva póliza de seguro colectivo o flotante". En consecuencia, no hay prueba que valga contra lo que expresa la póliza que surge de la celebración del contrato.

El artículo 515 del CCom no es más que la prolongación del artículo 514 del CCom., en cuanto al deber de información regulado en el inciso segundo de esta última norma. En otras palabras, la carga de la prueba sobre la existencia del seguro pesa sobre el asegurador y fija las condiciones en que se emitió la póliza, la que no admitirá prueba en contrario una vez emitido por parte del asegurador el certificado de cobertura definitivo. La

es mucho más amplio que el simple sistema de cuestionarios que se utiliza hoy extendidamente y procura entrega de datos que permiten a las compañías aseguradoras prever las posibilidades de siniestros y los comportamientos de los tomadores frente a estos. La máxima buena fe con que deben comportarse los tomadores de seguros exige develar esta información. No es una tecnología que no tenga reparos, los cuestionamientos más serios se dan en relación al límite de la información con la que se cuenta por la aseguradora, de hecho actualmente se discute en la Unión Europea si acaso este Big data no coloca en riesgo los datos personales o sensibles de los tomadores o consumidores. Sobre este tema, la interesante obra Mayer-Schönberger, Viktot y Cukier Keneth, (2013) Big Data: A Revolution That Will Transform How We Live, Work, and Think, Eamon Dolan/Houghton Mifflin, Nueva York, 242 pp. También, Illescas Rafael (2014) "Principios fundamentales del Contrato de Seguro”, en Revista Española de Seguros, num. 157, 2014, enero-marzo, pp.14, 94 pp. 
norma es meridianamente clara, la carga de la prueba del cumplimiento de esta obligación corresponde al predisponente, es decir, al asegurador.

Nos parece que esta es una interpretación consistente con el hecho de que el artículo 517 CCom. se enmarca dentro de los diferentes "Modos de contratar el seguro." Enumeración que comienza con el "Seguro por cuenta ajena”, en el artículo 516, y continúa con el artículo 517 CCom. precisamente con la "Contratación colectiva de seguros". Es decir, sobre estos artículos, 516 y 517 del CCom., rige de forma general el artículo 515 del CCom.

Los certificados de cobertura o certificados definitivos son, a juicio de Contreras, las llamadas "notas de cobertura", no definidas por el Código de Comercio, pero que se originan en el reaseguro, donde toman el nombre de "cover note", desde donde se habrían extendido en su uso al resto de los seguros ${ }^{20}$.

El certificado de cobertura definitivo no puede desligarse, en consecuencia, de la entrega de la póliza del artículo 519 del CCom. y la prima del artículo 527 del mismo cuerpo legal. Es precisamente el certificado definitivo el que reafirma el carácter consensual de los contratos de seguro y se inscribe ontológicamente en una mayor colaboración contractual entre las partes. Con certificado de cobertura o definitivo, el que se puede llamar de ambas formas, hay seguro, no queda duda. Es la ley la que tolera que los contratantes puedan fijar como inicio de los efectos del seguro aquel instante en el que acuerdan obligarse, aunque toda la documentación final se precise con posterioridad. Se permite, gracias al Certificado definitivo, que los efectos del contrato se retrotraigan al instante de la proposición o de la solicitud, en otras palabras, que el contrato se perfeccione antes de emitir la póliza.

¿Por qué el legislador trata separadamente al certificado provisorio y al certificado definitivo? Nos parece que el legislador trató separadamente el certificado de cobertura provisorio del definitivo, porque ligó el certificado definitivo a un seguro emitido con sujeción a los términos de una póliza de seguro colectivo o flotante. Es criticable esta opción y mueve a confusión, porque además de innecesaria como técnica legislativa, era perfectamente posible hacerse cargo del certificado de cobertura o certificado definitivo en el artículo dedicado a la contratación colectiva de segu-

20 Contreras Strauch, Osvaldo (2014) Derecho de Seguros, Segunda Edición, Editorial Legal. Publishing, Thomson Reuters, Santiago de Chile, pp. 160 y ss. Aclara también Contreras que: "similares a las pólizas de seguro flotante son aquellas denominadas pólizas de seguro con declaración mensual de valores. En ellas la Compañía aseguradora otorga en favor de determinado asegurado una póliza que cubre determinadas existencias (en caso de incendio o robo) o movimientos de transporte (en las pólizas de seguro de transporte), obligándose el asegurado a señalar una vez al mes, el valor efectivo de las existencias o de los movimientos realizados durante ese mes, para ajustar el cobro de la prima, la que en principio ha sido meramente estimada, en función de existencias o movimientos teóricos o históricos." 
ros, el 517 del Com., sin por ello tener que definirlo, porque nada aporta su definición realmente.

En efecto, es en la norma del artículo 517 del CCom. donde se senala, específicamente en el tercer inciso, su característica principal, ya que: "A través del tomador, el asegurador deberá entregar a cada uno de los asegurados que se incorporen al contrato de seguro colectivo, una copia de la póliza, o, al menos, un certificado que acredite la cobertura". En consecuencia, están obligados a informarse y respetarse las coberturas pactadas, de acuerdo a las necesidades de las personas, esto porque el consumidor es protegido por la ley primeramente en cuanto al acto de consumo, más estrictamente las expectativas prometidas por el proveedor, y luego, respecto del contenido de las obligaciones del contrato de seguro acordado.

Resulta deseable, y armónico con esta misma idea, que el certificado de cobertura, sea claro, preciso y ajustado a un lenguaje comprensible por el tomador y consumidor. Recordemos que de acuerdo al artículo 529 número 1 "el asegurador será responsable de las infracciones, errores y omisiones cometidos y de los perjuicios causados a los asegurados". En consecuencia, debiera considerarse como parte integrante de la cobertura aquello que no se explicite de manera clara y precisa por el asegurador y se pruebe que haya sido pedido considerar en su cobertura del riesgo por parte del tomador, ello también conforme al artículo 515, inciso segundo, del Código de Comercio que señala que "[L]a existencia y estipulaciones del contrato se podrán acreditar por todos los medios de prueba que contemplen las leyes, siempre que exista un principio de prueba por escrito que emane de cualquier documento que conste en télex, fax, mensajes de correo electrónico y, en general, cualquier sistema de transmisión y registro digital o electrónico de la palabra escrita o verbal". El artículo 12 de la ley 19.496, dispone que todo proveedor de bienes o servicios "estará obligado a respetar los términos, condiciones y modalidades conforme a las cuales se hubiere ofrecido o convenido con el consumidor la entrega del bien o la prestación del servicio". Lo que ha de respetarse es lo que se ofrece y, por ello, la información y lo entregado o no, es esencial al consumo de seguros. Los deberes de respeto de la información entregada surgen de la oferta que la aseguradora hace al público, finalmente.

Esta solución es armónica con los artículos 517 y 518 del Código de Comercio, que señalan como menciones esenciales de las pólizas los riesgos que se transfieren al asegurador y, gracias a su carácter imperativo, nos parece armónica también con el artículo 542 del Código de Comercio. En efecto, la imperatividad del artículo 542 del Código de Comercio, no debiera afectar al tomador de seguros si la nulidad proviene de infracciones, errores y omisiones cometidos y de los perjuicios causados a los asegurados durante la contratación del seguro, porque ellos son de responsabilidad del asegurador. En otras palabras, el asegurador, que es quien ejecuta el acto, sabía o debía saber el vicio que invalidaba el mismo, como 
reza el artículo 1683 del Código Civil, en consecuencia, no puede ejercer la acción de nulidad, aprovechándose de anular una relación jurídica en la que no desplegó adecuadamente su carga de información en desmedro del tomador.

En la práctica, el certificado de cobertura definitivo debiera incluir como mínimo a nuestro juicio: el hecho de haberse pagado la prima; la fecha y firma del asegurador o su intermediario; la fecha y firma del tomador o su representante legal y las cosas esenciales del contrato de seguro a que alude el artículo 521 del Código de Comercio. Sobre el pago de la prima, resulta absolutamente esencial que conste en el certificado de cobertura que se realizó, si es del caso, sin perjuicio de que es necesario también que en la póliza las fechas coincidan con la del documento de cobertura provisorio. Se expresa por el legislador, a nuestro juicio, una carga de entregar este documento a la aseguradora, por lo que el Certificado, al igual que sucede con el certificado provisorio, debiera estar en papel o en un medio físico duradero ${ }^{21}$.

En esta línea, es bueno recordar aquí los derechos propios de los consumidores ante esta oferta unilateral del asegurador, al menos en un par de aspectos, al igual que sucede con el certificado provisorio. El primero es que la oferta a persona indeterminada, en materia de formación del consentimiento en relaciones de consumo, obliga si de actos de esta especie se trata, ya que los artículos 12 y 12 A de la LPC así lo señalan. El segundo, es que el derecho de información exige todavía más intensidad que aquel propio de la formación del consentimiento en el Código de Comercio. Los artículos seńalados expresan que el acto de aceptación debe ser evidente, y de hecho se le asegura al consumidor el derecho a que el proveedor le envíe una confirmación en el propio artículo $12 \mathrm{~A}$ de la LPC. No podemos en este punto olvidar que los contratos de seguros, considerados estos como productos financieros, tienen un especial énfasis de protección ${ }^{22}$.

21 En el derecho español, y para el Diccionario Mapfre de seguros, el certificado de seguro (insurance certificate) es, en general, "el documento por el que un asegurador da fe de la existencia de ciertas coberturas sobre un determinado objeto o persona. Normalmente el certificado de seguro solo recoge las condiciones particulares del contrato y se remite, en lo que a condiciones generales respecta, a la póliza base previamente suscrita.” Disponible en: http://www.mapfre.com/wdiccionario/terminos/vertermino.shtml?c/certificado-de-seguro. htm , fecha de visita: 19 de julio de 2014 .

22 Ya desde el mensaje presidencial, se señalaba: "Por tanto, consideramos indispensables fortalecer la protección del consumidor de servicios financieros, de telecomunicaciones y de transporte público de pasajeros, entre otros, a través de la dotación de mayores atribuciones y competencias al referido Servicio Nacional del Consumidor, perfeccionando la entrega de información y realizando estudios que reduzcan las asimetrias de información. Estas atribuciones servirán también en otros mercados regulados de similares características al financiero." Ley publicada en el D.O el 5 de diciembre del 2011. La historia de la norma se encuentra disponible en: www.leychile.cl. [fecha de visita: 10 de marzo de 2013]. 
Un Certificado definitivo de cobertura, físicamente, es un resumen que no suele exceder de una página con toda aquella información sustancial comprendida en una futura póliza de seguro comercial. La información contenida suele incluir las limitaciones futuras de la póliza; el deducible; las principales áreas de cobertura; informaciones de las partes del contrato; fecha de caducidad de las pólizas; los nombres de cualquiera de las coberturas adicionales que contiene la póliza como, por ejemplo, asegurados adicionales o cláusulas particulares. Tienen especial importancia en los casos de seguros de responsabilidad civil porque a diario permiten a los contratistas y PYMES demostrar la existencia de un seguro y cobertura en las actividades que desarrollan.

En el derecho francés, y para corroborar la forma de entender el certificado de seguro que hemos expuesto para la legislación chilena, sin perjuicio del régimen de derecho común, el consentimiento ha de constar por escrito en los seguros, cuestión muy similar a la actual en el derecho chileno, conforme a los artículos L. 112-3, párrafo 1 del Código de Seguros de Francia. Esto, no obstante que el artículo L. 112-2, 4, del mismo cuerpo legal, señala que "solo la póliza o la nota de cobertura evidencian el compromiso recíproco" de las partes en contrato de seguro. En la práctica, la ley permite que se presente, como evidencia de la existencia del contrato de seguros, otros escritos tales como conseguir un certificado de cobertura o nota de seguros por parte de la compañía aseguradora ${ }^{23}$. Este certificado o nota de cobertura es tenido como uno provisorio en el Derecho francés, es un documento de resumen y establece la existencia de garantías o coberturas antes de que se emita la póliza. Su forma es muy amplia, puede constar en cualquier tipo de notas por escrito, cartas, mail, etc. Su única limitación de prueba es que debe emanar de la aseguradora o su representante, siendo esencial la especificación de las condiciones de garantía acordada y el tiempo de duración del certificado.

En conclusión, es propio de la práctica de seguros que el certificado de cobertura definitivo sea tenido como una clara manifestación de voluntad que forma el contrato de seguro y sus condiciones esenciales.

\section{3.) CONTENIDO DEL DEbER PRECONTRACTUAL DE INFORMACióN EN LA PROPUESTA DEL SEGURO}

El nuevo Art. 514 del Código de Comercio expresa qué es una propuesta:

"Propuesta. La proposición de celebrar un contrato de seguro deberá expresar la cobertura, los antecedentes y circunstancias necesarios para apreciar la extensión de los riesgos.

23 Chagny, Muriel y Perdrix, Louis (2013) Droit des assurances, Segunda Edición, Editorial L.G.D.J., Paris, pp. 128 y ss, 618 pp. 
Para estos efectos, el asegurador deberá entregar al tomador, por escrito, toda la información relativa al contenido del contrato que se celebrará. Esta deberá contener, al menos, el tipo de seguro de que se trata, los riesgos cubiertos y las exclusiones; la cantidad asegurada, forma de determinarla y los deducibles; la prima o método para su cálculo; el período de duración del contrato, así como la explicitación de la fecha de inicio y término de la cobertura”.

La propuesta o proposición de celebrar un seguro es, tal y como se expresó durante la tramitación en el Congreso Nacional de la ley 20.667, que modificó el Código de Comercio, un principio de prueba por escrito de la existencia del seguro, al que se suman todos los medios de prueba que contempla la ley y que no hace sino confirmar el nuevo carácter consensual del mismo contrato de seguros, y para los casos de seguros masivos, lisa y llanamente, de adhesión. Se sigue, con esta forma de perfeccionamiento del contrato de seguro, lo que se califica en la historia de la norma como una "corriente mayoritaria en el derecho comparado" 24 .

El artículo 514, que ingresó al Congreso como proyecto de ley, era bastante más escueto del que finalmente se aprobó, ya que solo comprendía el inciso primero de la norma publicada ${ }^{25}$. El proyecto presentado al Congreso, en lo que a propuesta se refiere, entiende que el contrato de seguro, tal y como expresó don Osvaldo Macías, "se va armando paso a paso no solo con la propuesta, sino con múltiples comunicaciones escritas, telefónicas y electrónicas, en las que se acota el riesgo y sus circunstancias" 26 .

Es por ello que la propuesta del seguro del artículo 514 del CCom, a poco andar, se entendió que debía ser vinculante, rasgo que mantuvo hasta la dictación del artículo en el texto definitivo. Fue durante la tramitación

24 Así, en el boletín N ${ }^{\circ}$ 5185-03. Moción de los Señores Diputados, Jorge Burgos Varela, Juan Bustos Ramírez, Alberto Cardemil Herrera, Edmundo Eluchans Urenda, Marcelo Forni Lobos, Renán Fuentealba Vildósola, Sergio Ojeda Uribe, Eduardo Saffirio Suárez, Patricio Vallespín López, Mario Venegas Cárdenas. Fecha 10 de julio, 2007. Cuenta en Sesión 47, Legislatura 355. La historia de la norma se encuentra disponible en: www.leychile.cl. [fecha de visita: 16 de junio de 2014]. pp. 6.

25 "Art. 514 Propuesta. La proposición de celebrar un contrato de seguro deberá expresar la cobertura y los antecedentes y circunstancias necesarios para apreciar la extensión de los riesgos". Así en la historia de la norma que se encuentra disponible en: www.leychile.cl. [fecha de visita: 16 de junio de 2014]. pp. 21. Durante la tramitación en el Congreso de esta norma, se produjeron una serie de intervenciones. Llama la atención la de don Osvaldo Macías, Intendente de Seguros de la Superintendencia de Valores y Seguros de la época, quien reconoció que: "poco a poco la realidad contractual y de legislaciones especiales, se fueron distanciando del contenido de las normas del Código de Comercio en materia de contrato de seguro, las que en algunos casos fueron superadas o resultaron inaplicables, forzando interpretaciones que permitiesen recoger nuevas realidades." Así en la historia de la norma que se encuentra disponible en: www.leychile.cl. [fecha de visita: 16 de junio de 2014]. pp. 70.

26 Así en la historia de la norma que se encuentra disponible en: www.leychile.cl. [fecha de visita: 16 de junio de 2014]. pp. 71. 
en el Senado que, en el segundo informe de la Comisión de Hacienda, ante una consulta del Senador Novoa, el Fiscal de Seguros de la Superintendencia de Valores y Seguros de la época explicó que, “jurídicamente, la propuesta del contrato de seguro puede ser formulada tanto por el asegurador como por el asegurado. En seguros masivos, de hecho, lo que existe es una propuesta permanente que los asegurados y tomadores recogen, suscribiendo lo que se ofrece. En otros casos, es el tomador o asegurado quien formaliza una propuesta al asegurador, quien la acepta o no"27.

Por su parte, la Coordinadora de Mercado de Capitales del Ministerio de Hacienda de la época, acotó, precisando el alcance de la propuesta, que "en los seguros masivos se está en presencia de los denominados contratos de adhesión. Los otros casos corresponden, por ejemplo, a la necesidad que una empresa tiene de asegurar una planta de operaciones, para lo que define cuáles son las coberturas que requiere y realiza una propuesta a un asegurador" ${ }^{28}$. Es precisamente ese el espíritu de la norma del inciso segundo de este artículo 514, inciso segundo, que lleva al tomador a entregar "por escrito, toda la información relativa al contenido del contrato que se celebrará" 29 .

El énfasis de esta disposición, que se extrae de la historia de ley, radica en que es el asegurador el que debe detallar el contenido de la información que debe entregar al asegurado una vez recibida la propuesta ${ }^{30}$, en los términos del artículo 513 letra q), con todos los problemas de interpretación que este plantea. Nos parece, por ello, que el legislador yerra en la delimitación del concepto de mismo de Propuesta, como por cierto en todo el artículo 513, el que debiera ser derogado en una futura revisión legislativa.

Así en la historia de la norma que se encuentra disponible en: www.leychile.cl. [fecha de visita: 16 de junio de 2014]. pp. 382.

Así en la historia de la norma que se encuentra disponible en: www.leychile.cl. [fecha de visita: 16 de junio de 2014]. pp. 382.

29 Don Osvaldo Contreras expresó, en la misma sesión en el Congreso, que: "normalmente, la propuesta de celebración se verifica con ocasión de los seguros individuales, en que el asegurado, en base a un cuestionario que le proporciona la compañía, le indica al asegurador qué cobertura requiere. Algo distinto acontece en otros contratos de seguros, en que una empresa grande llama a las aseguradoras a competir para adjudicarse su cartera de seguros. Y una tercera alternativa se verifica con ocasión de los seguros colectivos. A su entender, expresó, la redacción del artículo 514 se refiere solamente al primero de estos casos, en consonancia con la definición de propuesta del artículo 513. Y si se agregara el segundo inciso contenido en la indicación número 3, a mayor abundamiento, se estaría introduciendo un elemento de confusión, pues su redacción no se aviene con la idea de que es el asegurado quien formula una propuesta: por el contrario, se traspasa al asegurador la obligación de entregar una determinada información al tomador." Así en la historia de la norma que se encuentra disponible en: www.leychile.cl. [fecha de visita: 16 de junio de 2014]. pp. 382. visita: 16 de junio de 2014]. pp. 383. 
El artículo 513 q) debiera haberse empleado para definir, ya que lo hizo el legislador, qué es una proposición de seguro. La proposición de seguro es una solicitud del eventual tomador a la aseguradora, solicitando el seguro ante un determinado riesgo que se quiere traspasar a cambio del pago de una prima. De esta manera, la propuesta, que detalla la ley en el artículo 514 del CCom., solo es posible de realizar por la aseguradora, ya que debe precisar aspectos de variado contenido técnico, los que solo un profesional o perito puede determinar.

La propuesta debe ser carga de la aseguradora, sino no se entenderían los términos planteados por la ley 20.667, específicamente en el artículo 529 del CCom., que consagra como obligación del asegurador, en el número 1: "cuando el seguro se contrate de forma directa, sin intermediación de un corredor de seguros, prestar asesoría al asegurado, ofrecerle las coberturas más convenientes a sus necesidades e intereses, ilustrarlo sobre las condiciones del contrato y asistirlo durante toda la vigencia, modificación y renovación del contrato y al momento del siniestro. Cuando el seguro se contrate en esta forma, el asegurador será responsable de las infracciones, errores y omisiones cometidos y de los perjuicios causados a los asegurados."

Avala esta postura el expreso énfasis con que, durante la tramitación de la ley, en el Senado se cuestionara cuál era el valor finalmente del contrato de seguro, ya que "[S]i todas las negociaciones se traducen, finalmente, en un contrato que las partes suscriben, lo esperable sería que la certeza jurídica generada no pueda ser alterada" ${ }^{31}$. Visto así, la propuesta misma puede crear incerteza jurídica, como se mencionó ${ }^{32}$.

Nos parece que en este iter de creación del seguro, la propuesta cumple una función de garantía imprescindible que precisa de manera clara "al menos, el tipo de seguro de que se trata, los riesgos cubiertos y las exclusiones; la cantidad asegurada, forma de determinarla y los deducibles; la prima o método para su cálculo; el período de duración del contrato, así como la explicitación de la fecha de inicio y término de la cobertura" 33 .

Estimamos que la precisión de este contenido normativo, lejos de constituir un riesgo a la certeza jurídica, vincula al asegurador sobre las cosas esenciales en un seguro, el riesgo asegurado, la estipulación de prima y la obligación condicional del asegurador de indemnizar, lo que representa una clara ventaja para el asegurado. Aquí debieran quedar expresadas por

\footnotetext{
31 Así en la historia de la norma que se encuentra disponible en: www.leychile.cl. [fecha de visita: 16 de junio de 2014]. pp. 387. Intervención del Senador Jovino Novoa.

32 Así en la historia de la norma que se encuentra disponible en: www.leychile.cl. [fecha de visita: 16 de junio de 2014]. pp. 387. Intervención del Senador Eduardo Frei.

33 Así en la historia de la norma que se encuentra disponible en: www.leychile.cl. [fecha de visita: 16 de junio de 2014]. pp. 387. Intervención del Senador Eduardo Frei.
} 
las aseguradoras y los consumidores todas las delimitaciones temporales de cobertura, las cláusulas de cobertura retroactiva e incluso aquellas de cobertura posterior ${ }^{34}$. La propuesta exige, en este sentido, de parte de la aseguradora, la inspección de los riesgos ya que asume una función de garantía de un deber precontractual de información, determinante para la celebración e interpretación posterior del contrato de seguro ${ }^{35}$.

Resulta, por lo tanto, insoslayable que el artículo 514 del CCom debe ser concordado con el Artículo 17, letra B de la Ley 19.496, ya que el asegurador deberá entregar al tomador, por escrito, toda la información relativa al contenido del contrato que se celebrará. En efecto, la norma del Art. 17 Letra B de la LPC señala expresamente que debe señalarse: "c) la duración del contrato o su carácter de indefinido o renovable automáticamente, las causales, si las hubiere, que pudieran dar lugar a su término anticipado por la sola voluntad del consumidor (...)" con sus respectivos plazos de aviso previo. En consecuencia, la denuncia de cláusulas abusivas que pudieran alterar lo preceptuado por el artículo $17 \mathrm{~B}$ de la LPC, tal cual expresa Baraona, solo puede ser ejercida, para los efectos de pedir su nulidad por el consumidor y ellas no pueden ser invocadas por el proveedor para eximirse o retardar el cumplimiento parcial o total de las obligaciones que le imponen los respectivos contratos a favor del consumidor (artículo $17 \mathrm{E})^{36}$.

Hoy no queda duda que la oferta, como acto formador del contrato de seguro, consensual y de adhesión, descansa no en el tomador o asegurado consumidor, sino más bien en el asegurado proveedor. La carga de la prueba del cumplimiento de esta carga corresponde al predisponente, es decir, al asegurador. Se pretende con ello que el asegurado tenga la oportunidad de tomar conocimiento real de las cláusulas del contrato, antes de la celebración del mismo.

La información servirá para reducir la asimetría entre las partes, y en esto hay una clave, debe ser clara y precisa, estar a disposición siempre. Da lo mismo si el consumidor o tomador del seguro la va a leer o si no la entiende porque su nivel de comprensión intelectual es bajo. Esto es irrelevante, lo más importante es que fue simplemente capaz de haberla leído porque la aseguradora se la puso a disposición de la forma en que manda la ley. Este es el estándar que se habrá de satisfacer. El deber de información es una carga para el asegurador, nacida legalmente para integrar deberes precontractuales de comportamiento, los que pueden dar origen a responsa-

Sánchez Calero (2010) p. 1654.

Sobre este aspecto, en general, ver Ríos Ossa (2014).

BaraONA, Jorge (2014) "La regulación contenida en la ley 19.496 sobre protección de los derechos de los consumidores y las reglas del código civil y comercial sobre contratos: un marco comparativo", Revista Chilena de Derecho, Vol. 41 N², pp. 391. 
bilidad o culpa in contrahendo ${ }^{37}$. En este sentido, el suministro de información es uno de los principales requisitos para garantizar su protección.

\subsection{1.) Los fundamentos del nuevo artículo 529 número 1 del Código de Comercio en relación al deber precontractual de asesoría durante la vigencia, modificación y renovación del contrato e incluso el siniestro}

El conjunto de normas legales aprobadas en los tres últimos años en materias de seguros, leyes 20.555 y 20.667 , tienen como elementos fundantes la exigencia de claridad, sencillez y asesoría en la contratación de los seguros por parte de las compañías de seguros. Vienen expresamente consagrados de esta forma en las leyes citadas y tienen importantes consecuencias durante todo proceso de perfeccionamiento del contrato de seguros, lo que comprende la emisión de los certificados provisorios, definitivos y la propuesta de contratar seguros. Así, la ausencia de comprobante de aceptación o manifestación de voluntad nunca podrá entenderse como una forma de aceptación a una oferta en el contrato de seguro, salvo aquel de grandes riesgos. La validez de las aceptaciones tácitas queda restringida a aquellas que solo evidencien, de manera clara e inequívoca, una manifestación de la voluntad en términos de aceptación por parte del consumidor tomador.

Es una pretensión clara de la nueva reglamentación de seguros que el mercado asegurador cambie la forma de contratación y reconozca que su posición de privilegio en la redacción de los contratos no significa que pueda recurrir a redacciones ambiguas, coberturas innecesarias, remisiones internas entre condiciones generales y específicas de cobertura que hagan llegar a vaguedades, generalizaciones o imprecisiones del articulado de los contratos. Esto es especialmente sensible en las cláusulas relativas a las obligaciones esenciales del contrato y aquellas limitativas de los derechos de los asegurados. No cabe la menor duda que se han consagrado legalmente unos requisitos elementales de transparencia, que no tienen sino en la redacción de un clausulado comprensible y fácil de entender, su mayor realización.

Todo lo expresado ha quedado suficientemente ratificado por el boletín $\mathrm{N}^{\circ} 5185-03^{38}$, durante la tramitación de la ley 20.667 , en el que se

37 Barrientos (2008) Daños y Deberes en las Tratativas Preliminares de un Contrato, LegalPublishing, Santiago de Chile, pp. 7-47, 142 pp.; De LA MAZA (2010) Los Limites del Deber Precontractual de Información, Civitas, Madrid, pp. 59 y ss, 608 pp.; García RuBio y ОтеRо (2010) La responsabilidad precontractual en el Derecho contractual europeo (Indret) p. 23. fecha de visita: 19 de julio de 2014 .

38 Moción de los señores diputados, Jorge Burgos Varela, Juan Bustos Ramírez, Alberto Cardemil Herrera, Edmundo Eluchans Urenda, Marcelo Forni Lobos, Renán Fuentealba Vildósola, Sergio Ojeda Uribe, Eduardo Saffirio Suárez, Patricio Vallespín López, Mario Venegas 
expresó que el artículo 529 del CCOM, consagraba la principal obligación del asegurador, la de indemnizar el siniestro ${ }^{39}$. Sin embargo, no es la única, la primera y anterior es "una modificación de la mayor importancia en beneficio directo del asegurado" 40 .

Se trató de desterrar abusos que lamentablemente se detectan comúnmente, por parte de algunas compańías aseguradoras e intermediarios, con los tomadores de seguros. Se dijo en el Congreso, textualmente: "Es muy corriente que a los asegurados se les venda pólizas de seguro que no se adaptan a sus reales necesidades de cobertura, por montos inadecuados, que contienen coberturas innecesarias (riesgo de salida de mar para una casa ubicada en Santiago o un refugio en la nieve) y por el contrario, que no se le advierta respecto de los riesgos no cubiertos, como por ejemplo, que una póliza de seguro de incendio ordinario no cubre incendio a causa de terremoto. En todo caso en la inmensa mayoría de los casos el asegurado carece completamente de asesoría durante la contratación, al modificar o renovar las pólizas y principalmente al momento de reclamar el pago de un siniestro" ${ }^{41}$.

Los condicionados generales y particulares han presentado redacciones ambiguas en el pasado, en algunos casos deliberadamente ambiguas, con palabras técnicas innecesarias, llenas de contradicciones y en los que las condiciones generales del seguro no se condicen ni son congruentes con las condiciones particulares del mismo. Estamos frente a reglamentaciones predispuestas en los contratos en que ningún adherente podría determinar su cobertura sin dudas sobre su alcance. Queda, después de la lectura de no pocas pólizas, la pregunta de si ocurrido que sea el siniestro habrá o no cobertura. La ambigüedad es propia de aquellos clausulados generales en que las cláusulas son susceptibles de uno o más sentidos de interpretación y en los que los términos no aparecen claros de manera que generan imprecisión de cobertura, plazos inciertos, daños excluidos e incluidos en la cobertura al mismo tiempo, múltiples partes de un mismo contrato predispuesto por la aseguradora, dispersos en condicionados particulares y generales, que se contradicen entre sí, etcétera.

En este sentido, una sentencia relativamente reciente puede ilustrar sobre lo que venimos sosteniendo. El precedente es de la Corte de

Cárdenas. Fecha 10 de julio, 2007. Cuenta en Sesión 47, Legislatura 355. La historia de la norma se encuentra disponible en: www.leychile.cl. [fecha de visita: 16 de junio de 2014]. pp. 9.

39 Así en la historia de la norma que se encuentra disponible en: www.leychile.cl. [fecha de visita: 16 de junio de 2014]. pp. 14.

40 Así en la historia de la norma que se encuentra disponible en: www.leychile.cl. [fecha de visita: 16 de junio de 2014]. pp. 95.

41 Así en la historia de la norma que se encuentra disponible en: www.leychile.cl. [fecha de visita: 16 de junio de 2014]. pp. 95. 
Apelaciones de Talca de 2 de noviembre del $2011^{42}$. En esta causa, dońa Marta Espinoza Serrano demandó, en virtud de la Ley 19.496, por incumplimiento contractual, a la Compañía de Seguros Renta Nacional. La demandante contrató un seguro de incendio al cual se agregaron cláusulas de cobertura adicional. Esta ampliación de cobertura a otros siniestros contemplaban "inundaciones" y "desbordamiento de cauces", debidamente adicionados por el apartado adicional CAD 103034 . Ahí se expresaba que: "La presente cláusula cubre: Los daños causados a los bienes asegurados, por los incendios excluidos por el artículo 4 letra d) de las condiciones generales de esta póliza, que tengan su origen en la acción directa del viento sobre aquellos, o que fuere consecuencia de inundación o desbordamientos de cauces siempre que éstos tengan su origen en fenómenos de la naturaleza; b) Los daños materiales a consecuencia de la acción directa del viento sobre aquellos, o que fueren consecuencia de inundación o desbordamiento de cauces, siempre que éstos tengan su origen en fenómenos de la naturaleza". El título 2 sobre las "Exclusiones" disponía "Este adicional no cubre los incendios o daños causados por: a) salidas de mar (...) b) Incendio y daños materiales de origen sísmico, sea volcánico o telúrico". Resultaba de su sola lectura evidente una contradicción. Los hechos, materia del juicio, discurrían sobre si el agua que afectó la casa de la demandante provino del mar después del terremoto del 27 de febrero de 2010, o se debió a un aumento de cauce del río Mataquito que tuvo dirección sur a norte, es decir, si vino de una dirección opuesta al mar. Conforme a la cobertura del contrato de seguro, se debía establecer si los daños se produjeron por "salida de mar", excluida expresamente, o por un desbordamiento de cauce del río, incluido en la cobertura. Además, se debe tener presente que en el título 2 "Exclusiones" del contrato de seguro objeto de la litis, se disponía que "Este adicional no cubre los incendios o daños causados por: a) salidas de mar (...) b) Incendio y daños materiales de origen sísmico, sea volcánico o telúrico”³.

42 Corte de Apelaciones de Talca, de 2 de noviembre del 2011, rol 692-2011, "Espinoza Serrano, Marta/Compañia de Seguros Renta Nacional”. Microjuris: MJCH_MJJ29914 | ROL: 692-11, MJJ29914.

43 En la causa, la Compañía, quien tenía el onus probandi, no logró acreditar que los daños sufridos fueron ocasionados en una salida de mar o que estos tuvieran un origen sísmico o volcánico directo. Es cierto que el terremoto y tsunami del día 27 de febrero de 2010 en Chile produjo el aumento de cauce del río Mataquito, y la consecuente destrucción de la casa de la actora en juicio, pero no se pudo probar por la Compañía Renta Nacional si este hecho era asimilable a la exclusión que la eximía de indemnizar en caso de "salida de mar" o más bien se debía a "daños directamente ocasionados por fenómenos sísmicos o volcánicos". En consecuencia, procedía que se cumpliera con el pago de las coberturas pactadas por daños ocasionados por aumento del cauce del río por parte de la citada Compañía de seguros.

En el contrato había, además, una cláusula compromisoria, identificable con el número 23 del mismo, que sometía cualquier dificultad que se suscitara entre el asegurado, el contratante o el beneficiario, a conocimiento de un juez árbitro arbitrador, nombrado de común 
Antes de la reforma de la ley 20.667, este caso hubo de ser fallado recurriendo a las normas del Código Civil, es decir, el estatuto de protección del asegurado encontró mejor protección en la norma general y supletoria. El voto de mayoría, en el caso que nos ocupa, expresó: "Debemos considerar para la interpretación del presente caso, de infracción de la ley del consumidor por parte de una aseguradora, que nos encontramos ante un contrato de adhesión, redactado en su totalidad por la Compañía de Seguros demandada, por lo que cualquier ambigüedad o falta de claridad o precisión debe ser interpretada en su contra, en tal sentido el artículo 1566 del Código Civil expresa que no pudiendo aplicarse ninguna de las reglas precedentes de interpretación, se interpretarán las cláusulas ambiguas a

acuerdo por las partes, el que a falta de acuerdo debía ser nombrado por la Justicia ordinaria, pero en éste último caso, en carácter de árbitro mixto. En virtud de lo anterior, la defensa de la compañía de seguros demandada, en el comparendo respectivo, dedujo la excepción dilatoria de incompetencia del No 1 del artículo 303 del Código de Procedimiento Civil, la que fue rechazada en definitiva a fojas 41, así como también el recurso de apelación interpuesto subsidiariamente al recurso de reposición, en virtud de lo dispuesto en los artículos 32 y 33 de la Ley 18.287, sobre Procedimientos en Juzgados de Policía Local.

Efectivamente, el artículo 2 bis de la Ley 19.496 excluye de la aplicación de la LPC, a las empresas de servicios reguladas por leyes especiales, lo que no ocurre en la especie, pues con la entrada en vigor de la Ley No 19.955, que modificó la Ley del Consumidor e introdujo el artículo 2 bis de la LPC, solo el primero de los requisitos de aplicabilidad de la Ley del Consumidor originaria se mantiene vigente como requisito general, esto es que debe tratarse de una relación entre un proveedor y un consumidor, quedando excluidos, en cuanto requisitos generales, la necesidad de que el acto jurídico debía tener el carácter de mixto, es decir mercantil para el proveedor y civil para el consumidor, por un lado, y por el otro.

Por su parte, el requisito de que la actividad económica desarrollada por el proveedor que, según la Compañía de seguros, no se encuentra regulada por leyes especiales, no se condice con lo señalado en el nuevo artículo 2 bis de la LPC, ya que: "No obstante lo prescrito en el artículo anterior, las normas de esta ley no serán aplicables a las actividades de producción, fabricación, importación, construcción, distribución y comercialización de bienes o de prestación de servicios reguladas por leyes especiales, salvo: c) En lo relativo al derecho del consumidor o usuario para recurrir en forma individual, conforme al procedimiento que esta ley establece, ante el tribunal correspondiente, a fin de ser indemnizado de todo perjuicio originado en el incumplimiento de una obligación contraída por los proveedores, siempre que no existan procedimientos indemnizatorios en dichas leyes especiales".

De esta forma, y a través de la excepciones contempladas en las letras a), b) y c) del nuevo artículo 2 bis, y utilizando una redacción que da la apariencia de que la regla general de que los actos regulados por leyes especiales siguen excluidos del estatuto genérico de la Ley del Consumidor, el resultado es precisamente el inverso, pues hoy, la excepción es que no resulte aplicable la LPC, ello aunque la materia pueda entenderse regulada, además de por la Ley del consumidor, por alguna ley especial como la de seguros, según explica el voto de minoría del citado fallo. El tribunal de alzada en el fallo que comentamos cierra estas ideas, precisamente en el considerando decimotercero de su sentencia, al seńalar que al momento de resolución del asunto, debe tenerse especialmente presente que nos encontramos dentro del ámbito de la Ley de Protección al Consumidor, el que como se sabe, consagra un estatuto protector, conteniendo de modo evidente el principio de defensa del consumidor, el que se materializa en materia de interpretación, al igual que en los demás estatutos protectores -piénsese materia laboral-, en el principio in dubio pro consumidor, que significa interpretar dichas leyes de acuerdo a sus principios y finalidades inspiradoras, esto es, en caso de duda, protegiendo al consumidor, tomador del seguro, en cuanto contratante más débil. 
favor del deudor, pero las cláusulas ambiguas que hayan sido extendidas o dictadas por una de las partes, sea acreedora o deudora, se interpretarán contra ella, siempre que la ambigüedad provenga de la falta de una explicación que haya debido darse por ella, cuestión que resulta conforme con ámbito de protección de la Ley de Protección al Consumidor".

Se comprende, entonces, que el artículo 529 del CCOM, fuera aprobado por unanimidad en la Comisión de Economía de la Cámara de Diputados, consagrando como obligaciones del asegurador prestar "asesoría integral" al asegurado, en caso que el seguro fuere contratado en forma directa sin intermediación de un corredor de seguros, e indemnizar el siniestro cubierto por la póliza ${ }^{44}$.

En su paso por el Senado, quedaron aún más claras las características de este deber de asesoría integral. El entonces Senador Novoa acotó que: "así como el artículo 524 contiene las obligaciones del asegurado, el artículo 529 hace lo propio con las del asegurador. Entre estas, se encuentra la novedad de tener que informar al asegurado acerca de las coberturas que sean más convenientes a sus necesidades, en caso de que contraten sin la intermediación de corredores de seguros" 45.

La reforma de la ley 20.667 al Código de Comercio, corrige una situación injusta hasta ahora en la legislación chilena, ya que si el contrato de seguros se contrataba por un intermediario, es decir, un corredor independiente, este tenía la obligación legal de asistir al asegurado durante todos esos procedimientos y respondía de los perjuicios que le causara por incumplimiento o cumplimiento defectuoso de sus obligaciones, en virtud del Arts. 57 y 58 del DFL No 251 de 1931. El artículo 57 del DFL $\mathrm{N}^{\circ} 251$, expresa que los seguros pueden ser contratados ya sea directamente con la entidad aseguradora, a través de sus agentes de ventas, o por intermedio de corredores de seguros independientes de estas, los que

Así en la historia de la norma que se encuentra disponible en: www.leychile.cl. [fecha de visita: 19 de julio de 2014]. pp. 130. Votaron a favor la Diputada señora Zalaquett y los Diputados señores Arenas, Chahín, Marinovic, Montes y Tuma.

45 Así en la historia de la norma que se encuentra disponible en: www.leychile.cl. [fecha de visita: 19 de julio de 2014]. pp. 382. Se observó que era un complemento del artículo 514, relativo a la propuesta del contrato de seguro. De ahí que se modificara levemente su redacción, sacando la frase: "o por intermedio de sus agentes de ventas", y dejando la siguiente: "sin intermediación de un corredor de seguros" en la parte primera del número 1 del artículo 529 número 1 del CCom. Fue por ello que el entonces Fiscal de Seguros de la Superintendencia de Valores y Seguros, seńor Zaldívar, sostuvo que "adquiere importancia en relación con el artículo 515 de la iniciativa, sobre celebración y prueba del contrato de seguro. Esta última disposición, en su inciso segundo, alude a cualquier "principio de prueba por escrito" como medio para acreditar la existencia y estipulaciones del contrato. Desde una perspectiva regulatoria y de supervisión, argumentó, no debe escapar al análisis el hecho que si el asegurador se encuentra en el deber de proporcionar, por escrito, información relativa al contenido del contrato, el requisito del referido principio de prueba se verá satisfecho." Así en la historia de la norma que se encuentra disponible en: www. leychile.cl. [fecha de visita: 19 de julio de 2014]. pp. 383 
además deben registrarse como tales y quedan sujetos a fiscalización, de acuerdo al inciso tercero.

$\mathrm{Su}$ responsabilidad es amplia y puede extenderse a la entidad aseguradora. Así lo señala el inciso tercero del artículo 57 del DFL $\mathrm{N}^{\circ} 251$ : "Serán de responsabilidad de la entidad aseguradora las infracciones, errores $u$ omisiones en que puedan incurrir los agentes de ventas en el desempeño de su actividad".

Por su parte, ya esta misma norma consagra un deber de asesoría, que es bastante similar al contenido del artículo 529 número 1 de la ley 20.667: "Los corredores de seguros son auxiliares del comercio de seguros, que deben asesorar a la persona que desea asegurarse por su intermedio, ofreciéndole las coberturas más convenientes a sus necesidades e intereses e ilustrándola sobre las condiciones del contrato, debiendo asistirla durante toda su vigencia, especialmente en las modificaciones que eventualmente correspondan y al momento de producirse un siniestro. Deben también asesorar a la compañía aseguradora verificando la identidad de los contratantes, la existencia de los bienes asegurables y entregándole toda la información que posean del riesgo propuesto".

La norma final del artículo 529 número 1 consagra una norma similar al artículo 10 del Decreto 1055, que entró en vigencia el 30 de noviembre de 2013, y que expresa dentro de las Obligaciones de corredores de seguros, que estos "estarán obligados a:

1) Asesorar a las personas que deseen asegurarse por su intermedio, ofreciéndoles las coberturas más convenientes a sus necesidades e intereses.

2) Informar a sus clientes sobre las condiciones del contrato y, en especial, sobre la extensión del seguro pactado y sus adicionales, sobre los riesgos y situaciones excluidas de la cobertura, alcance de las franquicias o deducibles a la misma, cláusula de prorrateo, forma y plazos de pago, efectos de su incumplimiento y, en general, toda la información necesaria para ilustrar mejor su decisión.

3) Asistir al asegurado durante toda la vigencia del contrato, especialmente en las modificaciones que eventualmente correspondan y al momento de producirse un siniestro".

Es por todo lo expresado, que no se entendía por qué las compañías de seguros no tenían consagración legal de un deber de asesoría y, por ello: “c) Es de toda lógica que se extienda dicho sistema de responsabilidades al propio asegurador cuando el asegurado contrata directamente con él o con sus agentes de ventas. No tiene lógica que si el asegurado contrata por intermedio de un corredor esté legalmente protegido de los errores y omisiones incurridos en la contratación y en cambio no lo esté cuando contrata directamente con el asegurador" 46 .

46 Así en la historia de la norma que se encuentra disponible en: www.leychile.cl. [fecha de visita: 18 de julio de 2014]. pp. 96. 
En razón de lo expuesto, es posible afirmar que la obligación legal actual del CCOM de facilitar la información precontractual, tiene por objeto que la compañía de seguros suministre aspectos técnicos, jurídicos y económicos que permitan una adecuada formación del consentimiento entre las partes, obligación, por cierto, del que el consumidor tomador del seguro es un acreedor.

La restricción de la libertad contractual, no debe olvidarse, ahora es ostensible en la contratación de los seguros. La incorporación de la ley 19.496 a esta dinámica de contratación añadió el artículo 4 de la LPC, en términos de irrenunciabilidad de derechos anticipadamente, a los contratos que se celebren. Se aleja para siempre el marco de holgura que brindaba el artículo 12 del Código civil y deja prohibida la renuncia anticipada de aquellos derechos dados por la ley a los consumidores tomadores de seguros. Ello, además, con una clara propuesta de guía de la libertad contractual, la que ha de expresarse al amparo del artículo 3 letra a) de la LPC, que asegura la libertad de elección del bien o servicio y resguarda que el silencio no constituya aceptación en los actos de consumo.

No basta ahora que las compañías de seguros respeten las buenas prácticas comerciales, ni siquiera la buena fe o la mera libertad contractual o los condicionados depositados en la SVS, se ha de garantizar, más bien, que los seguros tomados, y el uso en calidad de consumidor de los mismos, no se materialice en condiciones no respetadas, falta de transparencia, diferencias entre los ofrecido y lo efectivamente cubierto o ser sometido a prácticas económicas desleales.

\subsection{2) Influencia de la ley de contratos de seguros alemana de $\mathbf{2 0 0 8}$ en el deber precontractual de información y asesoría propio de los certificados de cobertura y la propuesta de seguro}

El nuevo deber de asesoría al asegurado en relación al ofrecimiento de las mejores coberturas posibles, considerando las necesidades e intereses del tomador, el que por cierto comprende la ilustración del contrato y la asistencia durante toda la vigencia, modificación, renovación y al momento del siniestro, reconoce su fuente en la Gesetz über den Versicherungsvertrag o Ley alemana de seguros de 2008. El legislador chileno se basó completamente en esta legislación, expresamente ${ }^{47}$.

\footnotetext{
47 "d) La reciente ley sobre contrato de seguro de Alemania, que entró en vigencia en Enero de 2008 ha introducido una norma similar a la que propone (art.7), que va en directo beneficio y protección del asegurado y de la seriedad del sistema de seguros, encontrando unánime acogida en la doctrina mundial. Desde luego, cabe mencionar que ha sido acogida por la Comunidad Europea, que ha dictado una directiva haciendo aplicable dicho sistema de responsabilidades a toda la Unión." Así en la historia de la norma que se encuentra disponible en: www.leychile.cl. [fecha de visita: 18 de julio de 2014]. pp. 96.
} 
Resulta imprescindible entonces remitirse y conocer el $\$ 7$ Information des Versicherungsnehmers de la ley alemana, en cuanto al deber de asesoría, el que señala que la aseguradora deberá informar al tomador, por escrito, de sus condiciones de contratación, incluyendo los términos y condiciones generales de los seguros, con la suficiente antelación, y siempre antes de que el tomador dé su aceptación contractual. Esta información se facilitará de manera clara y comprensible, de acuerdo con el medio de comunicación empleado ${ }^{48}$.

La importancia de esta norma la deja de manifiesto Osvaldo Contreras al señalar: "Sirvió de acicate para legislar en este sentido, el muy completo sistema que contempla respecto de este tema, la nueva ley alemana sobre el contrato de seguro, que entró en vigencia el $1^{\circ}$ de enero de 2008 . Como consecuencia de esta nueva norma, el asegurado puede requerirle, no solo al corredor o a los agentes del asegurador, sino a este mismo, la asistencia que requiera en conexión con los seguros que desea contratar o que haya contratado, en la forma y oportunidad que los Artículos 529 1) del C.Com. y el art. 57 del D.F.L. $N^{\circ} 251$ " 49 .

Si esto es así, consideramos que el sistema de registro de póliza debiera suprimirse. En efecto, el alcance del sistema actual de contratación de seguros modifica la formación del consentimiento en este contrato. El depósito de pólizas no cumple ahora ninguna función, ya que el contrato es consensual, por lo que se prueba por todos los medios de prueba que contemplen las leyes, siempre que exista un principio de prueba por escrito, que emane de cualquier documento que conste en telex, fax, mensajes de correo electrónico y, en general, cualquier sistema de transmisión y registro digital o electrónico de la palabra escrita o verbal. En consecuencia, las cláusulas contenidas en las pólizas no pueden infringir las normas del Título VIII del Libro II del Código de Comercio, porque en virtud del art. 542, todas ellas son imperativas, salvo en cuanto a que las estipulaciones contractuales sean más beneficiosas para el asegurado y, excepción hecha también, que se trate de seguros de grandes riesgos ${ }^{50}$.

El registro de pólizas está previsto en Chile en el art. $3^{\circ}$ letra e) del D.F.L. N ${ }^{\circ}$ 251. Con la imperatividad del artículo 542 del Código de Comercio, es muy discutible que el sistema contemple la obligatoriedad de usar solo pólizas que figuren inscritas en el "Depósito de Pólizas" a cargo de la Superintendencia de Valores y Seguros. Dos son las razones que avalan esta conclusión. La primera es que no hay un examen de legalidad

48 Disponible en http://www.gesetze-im-internet.de/vvg_2008/_7.html [fecha de visita: 19 de julio de 2014].

49 Contreras Strauch, Osvaldo (2014) Derecho de Seguros, Segunda Edición, Editorial LegalPublishing, Thomson Reuters, Santiago de Chile, pp. 266.

50 En el mismo sentido, Contreras Strauch (2014) 42. 
por parte de la SVS de las pólizas depositadas "a priori”. Si lo hay, segunda razón, es “a posteriori”, y siempre que el modelo de póliza depositado no cumpla con los requisitos de legalidad y claridad en su redacción, o con las normas mínimas que deberán contener las pólizas fijadas por la SVS, la que mediante una norma de aplicación general, podrá prohibir la utilización de dicho modelo de póliza o cláusula ${ }^{51}$. Este es el tenor del inciso final del art. $3^{\circ}$, letra e), D.F.L. $N^{\circ} 251$ de 1931. No creemos que la autoridad administrativa pueda hacer un examen sobre disposiciones imperativas, de orden público, las que creemos que solo toca a la autoridad judicial interpretar. En consecuencia, creemos que el inciso final del art. $3^{\circ}$, letra e), D.F.L. $\mathrm{N}^{\circ} 251$ de 1931, ha sido tácitamente derogado por el artículo 542 del Código de Comercio.

En esto, la legislación chilena ha seguido la misma línea trazada por la reforma alemana de 2008. Allí surgió una situación muy parecida a la que se vivía en Chile, tal y como explica Römer "[E]l principal objetivo de la nueva ley, por lo tanto, es mejorar la protección de los consumidores de manera significativa. Al mismo tiempo, y de acuerdo con las normas mínimas para los distintos sectores (...) El objetivo no es solo mejorar la protección de los consumidores, sino que también se posibilite la revisión y tutela de los deberes de los asegurados, la cancelación y terminación del seguro. Por encima de todo, la nueva Ley de Contrato de Seguro establece una mejora integral de las funciones de información y asesoramiento a los consumidores" 52 .

51 Sobre el sistema de pólizas, Arellano Iturriaga, Sergio (2013) La ley del seguro, LegalPublishing Thomson Reuters, Santiago, p. 26.

52 Römer Wolfgang (2009) Die Reform des Versicherungsvertragsrechts", en Humboldt Forum Recht, 13/2009, p. 3, 13 pp. Disponible en http://www.humboldt-forum-recht.de/ english/13-2009/beitrag.html [fecha de visita: 19 de julio de 2014]. En el año 2000, el entonces Ministro Federal de Justicia, Prof. Däubler-Gmelin, crea una comisión para la reforma de la ley de contrato de seguro. Esta Comisión estuvo integrada por 22 expertos como miembros. Después de un informe provisorio de 30 de mayo de 2002 concluyó su labor con un informe final de 19 de abril de 2004. Este informe final fue base esencial del proyecto de ley de 13 de marzo de 2006, del Ministerio Federal de Justicia. Se tomaron en cuenta observaciones de la Corte Constitucional Federal. Se invitó a las asociaciones y otras instituciones a hacer comentarios. La nueva Ley de Contrato de Seguro fue promulgada el 23 de noviembre de 2007. Como puede apreciarse se consultó exhaustivamente a expertos, teniendo en cuenta la literatura y dogmática de corriente principal alemana y recogiendo las opiniones de la industria de seguros y grupos de consumo que están bajo la supervisión de profesionales del Ministerio Federal de Justicia. Hay otros temas principales abordados en el centro de la reforma de la ley alemana, entre ellos la abolición del llamado "principio del todo o nada" y su sustitución por una regla de proporcionalidad. Se evita con ello que las aseguradoras se desentiendan de su responsabilidad total en situaciones específicas donde no se cumplían exactamente todos los requisitos de indemnización. Se agregaron normas legales sobre cumplimiento y responsabilidad en los casos de pérdidas materiales (ex $\$ 61$ ICA 1908) y en los casos de incumplimiento de deberes (Obliegenheiten), incluyendo el incumplimiento de la obligación de declaración contractual (ex $\$ 21$ ICA 1908), las obligaciones relativas a la agravación del riesgo (ex $\$ 25$ ICA 1908), de Obliegenheiten contractualmente impuesto (ex 
Hacia dónde debiera irse, a lo que desarrolló el sistema actual alemán. A una reforma que termine en Chile con el sistema o modelos de pólizas como únicas formas de perfeccionamiento del contrato de seguro. Este sistema se abandonó en Alemania porque la póliza es efectivamente un documento tardío dentro de la celebración del contrato, que no es conocido en su integridad por el tomador consumidor del contrato sino en un momento muy posterior a la de celebración del contrato. Ayuda el sistema de registro de pólizas a la inercia propia del tomador que confía, generalmente demasiado en el asegurador, y que, ante el cúmulo de condiciones planteadas y exceso de información, termina por abandonar la tarea colaboradora en la redacción del contenido de la póliza ${ }^{53}$.

Fue en virtud de este mandato legal que se dicta un Verordnung über Informationspflichten bei Versicherungsverträgen ${ }^{54}$ o Reglamento sobre los requisitos de información para los contratos de seguros ${ }^{55}$.

$\$ 6$ ICA 1908), etc. Sobre ello, Heiss, Helmut (2012) Proportionality in The New German Insurance Contract Act 2008, Erasmus Law Review, Volume 5, Issue 2 (2012), p. 106, 104114 pp.

53 Prueba de lo anterior es que muy rara vez, en la práctica de creación de seguros previa a la reforma de 2008 de la ley alemana de seguros, el tomador o eventual tomador no estuvo de acuerdo con lo que el predisponente asegurador le señalaba, y esto no se debía precisamente a una asistencia o buen consejo por parte del representante de la aseguradora. RöMER WoLFGANG (2009), p. 6.

54 Al determinar las características del contrato de seguro y la información requerida para su perfeccionamiento, por expreso mandato del legislador alemán, toda la norma interna alemana ha quedado alineada en conformidad con la Directiva 92/49/CEE del Consejo, de 18 de junio de 1992, sobre coordinación de las disposiciones legales, reglamentarias y administrativas relativas al seguro directo distinto del seguro de vida y sus modificaciones relativas a las Directivas 73/ 239/EEC y 88/357/CEE (DOCE L 228 p. 1), la Directiva 2002/65/CE del Parlamento Europeo y del Consejo, de 23 de septiembre de 2002 relativa a la comercialización a distancia de servicios financieros y las modificaciones de la Directiva del Consejo 90/619/CEE del Consejo y las Directivas 97/7/CE y 98/27/CE (DOCE L 271 p. 16), así como la Directiva 2002/83/CE del Parlamento Europeo y del Consejo, de 5 de noviembre de 2002, relativa el seguro de vida (DO CE L 345 p. 1).

55 Este señala que la aseguradora debe tener siempre disponible la identidad legal de la aseguradora y sus filiales, el domicilio legal de la aseguradora y cualquier otra dirección geográfica que proceda para las relaciones del cliente entre el asegurador, su agente o de otro comercio, persona o empresa relacionada y el tomador del seguro, el caso de las personas jurídicas, sociedades de personas o grupos también el nombre de un representante autorizado. Asimismo, debe informar el principal negocio de la compañía de seguros; la información acerca de la existencia de fondos de garantía u otros mecanismos de indemnización no abarcados por la Directiva 94/19/CE del Parlamento Europeo y del Consejo, de 30 de mayo de 1994 sobre los regímenes de garantía de depósitos (DO L 135, p 5) y la Directiva 97/ 9/EC del Parlamento Europeo y del Consejo, de 3 de marzo de 1997, sobre indemnización de los inversores (DO L 84, p 22); Nombre y se especificará la dirección del Fondo de Garantía; las condiciones aplicables a las condiciones generales del contrato de seguro, incluyendo las regulaciones arancelarias; las características esenciales de la prestación del seguro, incluyendo información sobre la naturaleza, alcance y oportunidad de los beneficios por parte de la aseguradora; el precio total del seguro, incluyendo todos los impuestos y otros componentes del precio, donde las primas deben notificarse por separado, y si el contrato de seguro incluye una serie de contratos de seguros independientes, o si el precio exacto no se puede 
La ley alemana de seguros reconoce expresamente que el tomador podrá, en cualquier momento pedir los documentos justificantes del período de cobertura y los términos del contrato, incluyendo los términos y condiciones generales de los seguros y que los costos del primer envío de esta información correrán de cargo de la aseguradora. La norma alemana excluyó de estas normativas los grandes riesgos, algo similar a lo ocurrido en Chile.

En la nueva reglamentación alemana, el asegurador o el mandatario de este deberán presentar al tomador potencial, antes de que preste su consentimiento, las condiciones generales de seguros y toda otra información, por escrito, y antes de que se presente la propuesta de aseguramiento. El que intermedie los seguros, o en su caso la propia aseguradora, debe guiar y asesorar al eventual tomador por numerosos tipos de términos y condiciones del seguro.

No cabe la menor duda que una de las desventajas que crea este modelo es la gran cantidad de tiempo que demoran los contratos de seguro por la impresionante cantidad de información. Sin embargo, la propia

indicar, la información sobre la base de su cálculo de que el tomador del seguro con un comentario que permita determinar el precio; en su caso, los gastos adicionales, indicando el importe total a pagar, así como otros posibles impuestos, tasas o gastos que no se pagan a través de la aseguradora y las prestadas por él; especificar todos los costos incurridos por el Asegurado para el uso de los medios de comunicación a distancia, si se cobrará dicho costo adicional; las modalidades para el pago y cumplimiento, en particular, para el pago de las primas; la limitación de la duración de la validez de la información proporcionada, por ejemplo, la validez de las ofertas limitadas, especialmente en términos de precio; en su caso, una indicación de que los servicios financieros relativos a los instrumentos financieros que se encuentran sujetas a riesgos debido a sus características específicas, o de las operaciones que se llevarán a cabo con riesgos específicos o sus fluctuaciones de precios, ello porque el mercado financiero en algunas oportunidades, y en el pasado reciente alemán, reflejó cantidades que no fueron indicativos de los resultados futuros; las circunstancias y los riesgos deben ser descritos; la información sobre cómo se celebra el contrato, en particular, el inicio de la cobertura del seguro y los seguros, así como la duración del período durante el cual el solicitante debe adjuntar a la solicitud; la existencia o inexistencia de un derecho de desistimiento y las condiciones, modalidades de ejercicio, en particular, el nombre y dirección de la persona que puede ejercer la revocación del seguro, y los efectos de la abstinencia, incluyendo información sobre la cantidad, en caso de desistimiento del seguro por parte del tomador del seguro; información del tiempo de ejecución y, en su caso, la duración mínima del contrato; información sobre la terminación del contrato, en particular, a las condiciones de terminación contractuales, incluidas las sanciones; la jurisdicción competente; los idiomas en que se comunican los términos del contrato y se hace referencia en esta disposición a la información previa, y los idiomas en que el asegurador se compromete a conducir con el consentimiento del titular de la póliza para comunicarse durante la vigencia de este Acuerdo; los procedimientos y recursos posibles por interpretación del contrato y, en su caso, las condiciones de dicho acceso; se debe hacer constar expresamente que la posibilidad de que los asegurados puedan obtener reparación no se ve afectado; Nombre y dirección de la autoridad de supervisión competente y de la posibilidad de presentar reclamaciones a la autoridad; la forma de envío del contrato, incluidas todas las Condiciones Generales que hemos detallado. Disponible en http://www.gesetze-im-internet.de/vvg-infov/ [fecha de visita: 19 de julio de 2014]. 
industria alemana se ha encargado de mitigar estos efectos por la entrega de información vía correos electrónicos y el uso intensivo de las firmas y certificados electrónicos.

El segundo modelo seguido, para satisfacer la información y asesoría del consumidor tomados, es actualmente en Alemania la llamada "Invitatiomodell". Un sistema en que el eventual asegurado o interesado llena un formulario de la aseguradora con todas las preguntas cuyas respuestas decidirán la suscripción por parte del asegurador del contrato. Estamos ante una Invitatio a la aseguradora, por la que esta puede enviarle una oferta. No estamos ante una declaración de contrato. Aquí, recibida la declaración del riesgo del cliente, la compañía de seguros envía al cliente potencial la póliza con los otros documentos del contrato. Este proceso es considerado como una oferta para la conclusión de un contrato. La oferta se presenta en este caso por parte de la aseguradora. La ventaja de este modelo es que el futuro cliente según $\$ 7$ párrafo 1 frase primera de la ley alemana de seguros ya ha recibido todos los documentos contractuales antes de consentir en un contrato vinculante ${ }^{56}$.

\section{2) NORMAS ADMINISTRATIVAS MODIFICADAS RECIENTEMENTE SOBRE EL DEBER DE INFORMACIÓN AL MOMENTO DE CELEBRACIÓN DEL CONTRATO DE SEGUROS Y LA ASESORÍA LEGAL OBLIGATORIA}

La Superintendencia de Valores y Seguros (en adelante SVS), en la Circular número 2126, ha seńalado que en la propuesta de seguros los corredores deberán hacer constar, por escrito, las propuestas de seguros que reciban para su intermediación. Su redacción es prácticamente igual a la referida en el artículo 514 inciso segundo actual del Código de Comercio, solo agregándose que también deberá indicarse el nombre y RUT del corredor y de quien intervino por cuenta de él.

La NCG 347 se relaciona también con el art. 514 de la ley 20.667, limitando la fecha de vigencia de la oferta ${ }^{57}$. Esta norma modificó la

RÖMer Wolfgang (2009) p. 7.

Ver en depósito de pólizas www.svs.cl. [fecha de visita: 23 de diciembre de 2013]. La NCG 347 tiene vigencia desde el 1 de julio de 2013 y se aplica a todas las licitaciones que deban iniciarse a contar de esa fecha. Disponible en www.svs.cl (fecha de visita 5 de enero de 2013). La norma fue dictada según lo dispuesto en el artículo 40 del D.F.L. $\mathrm{N}^{\circ} 251$, de 1931, y las facultades que confiere la ley a las Superintendencias de Valores y Seguros y de Bancos e Instituciones Financieras. Son instrucciones de cumplimiento obligatorio para los bancos, cooperativas, agentes administradores de mutuos hipotecarios endosables, cajas de compensación de asignación familiar y cualquier otra entidad que tenga dentro de su giro otorgar créditos hipotecarios, y a las Compañías de Seguros de Vida y de Seguros Generales. Para los efectos de esta norma reglamentaria, también serán consideradas entidades crediticias las sociedades inmobiliarias, respecto de los seguros que deban contratar en virtud de 
NCG 330, especialmente en lo que respecta a las licitaciones de las compañías de seguro y a los deberes de información. En cuanto a los deberes de información, el número 2 del título II, exige informar al asegurado sobre la cobertura en un seguro colectivo y señala, específicamente, que su consentimiento conste por escrito, lo que está en plena sintonía con la interpretación que se ha impuesto para la formación del consentimiento en la LPC, puntualmente, en relación a los artículos 17 y siguientes de la ley 19.496.

¿Puede la autoridad administrativa interpretar deberes legales de información y que emanan de normas de carácter imperativo? Estimamos que excede con mucho sus atribuciones en esta materia, no creemos que tenga competencia para ello. Arribamos a esta conclusión de la simple lectura del artículo 542 del CCOM, puesto que las disposiciones que rigen el contrato de seguro son imperativas y solo "se entenderán válidas las estipulaciones contractuales que sean más beneficiosas para el asegurado o el beneficiario". Por lo tanto, si las normas reglamentarias emanadas de la autoridad administrativa, en virtud del DFL 251, especialmente en su artículo $3^{\circ}$, desconocen, rebajan o limitan las prerrogativas del tomador del seguro en cuanto a sus derechos consagradas en la ley, como es el caso del deber de información, estas disposiciones carecerán de valor por el orden público de protección a favor del contratante más débil expresado en el CCom y la LPC y en una correcta interpretación, deberán ser consideradas como nulas por aplicación del artículo 10 del Código Civil.

En la Circular 2148 de la SVS, de 8 de abril de 2014, se expresa que es responsabilidad de las compañías de seguros y corredores de seguros, en su caso, que la comercialización telefónica de seguros se realice en forma segura, íntegra y confidencial, respetando los derechos de los clientes asegurables y las normas legales, reglamentarias e instrucciones a que se sujetan las entidades aseguradoras y corredores de seguros.

La aseguradora o el corredor deberán proporcionar mecanismos para efectuar consultas y comunicaciones, debiendo siempre otorgar al asegurado un comprobante, código o número de recepción de estas, al momento de efectuarse. La comercialización telefónica de seguros, regulada por esta circular, puede utilizarse para suscribir pólizas individuales y para incorporar asegurados en pólizas colectivas, directamente por el asegurador o por medio de sus agentes de ventas o a través de corredores de seguros (oferentes) $)^{58}$.

los contratos de arrendamiento de vivienda con promesa de compraventa, celebrados en conformidad a lo dispuesto en la ley $\mathrm{N}^{\circ} 19.281$.

58 Es de destacar la reciente Circular 2123, de 22 de octubre de 2013, que imparte instrucciones sobre: información a incluir en pólizas de seguros; información de las primas y comisiones; reglas para seguros contratados en forma colectiva; normas generales sobre información a entregar al público acerca del asegurador y corredor de seguros, y; normas sobre promo- 
La utilización de servicios de empresas de telemarketing, que provean los medios de contacto con los asegurables, solo podrá efectuarse bajo la dirección, supervisión, control y responsabilidad de los aseguradores o corredores.

En el punto III. Requisitos DE INFORMACión PREVIA AL CONTRATO, se señala que "El oferente deberá proporcionar toda la información relevante al destinatario de la oferta y facilitarle los medios para efectuar consultas o decidir sobre la oferta del seguro.

En la promoción u oferta el oferente deberá informar y dejar registro, al menos, de lo siguiente:

1. Fecha en que se efectúa la oferta;

2. Identificación del oferente, compañía de seguros respectiva y demás copartícipes en la promoción u oferta de seguro;

Tratándose de seguros colectivos, deberá indicarse que se está ofreciendo la incorporación como asegurado a una póliza o contrato de seguro colectivo cuyas condiciones han sido convenidas por.......... (indicar nombre del contratante) directamente con la compañía de seguros.

Lo anterior no obsta al cumplimiento de las demás disposiciones de la Circular $\mathrm{N}^{\circ} 2123$.

3. Características del seguro, indicando las coberturas ofrecidas, condiciones especiales de asegurabilidad, exclusiones, carencias, deducibles, franquicias, duración del contrato, causales de término anticipado, vigencia y suma asegurada;

ción, publicidad y oferta de seguros y de beneficios asociados a la contratación de pólizas de seguros. En lo relativo a las reglas para información de la prima y condiciones, en el punto II, se señala que: "2. Para el cumplimiento de lo dispuesto en este número, en las condiciones particulares de la póliza o en el certificado de cobertura, cuando corresponda, las compañías deberán atenerse a las siguientes instrucciones:

2.1 La indicación en la póliza de las comisiones debe incluirse en los mismos caracteres que el resto de la información contenida en las condiciones particulares, tanto en su formato como en el tamaño y tipo de letra, y ubicarse en un lugar de fácil lectura.

2.2 El monto de las comisiones se deberá indicar solo con las palabras "comisión del corredor", "comisión de asesor previsional" o "retribución o comisión por venta del agente", según corresponda. En caso de otras comisiones distintas a las antes referidas, se deberá indicar con precisión la entidad que la percibe y el servicio a que se refiere.

2.3 Si las comisiones se estipulan como un porcentaje de la prima, deberá indicarse claramente la mención "\% de la prima” y si corresponde a prima bruta o neta.

En caso de indicarse la comisión en una moneda o unidad, debe identificarse clara e inequívocamente la moneda o unidad empleada ( $\$$, UF, dólar u otra).

2.4 En los casos en que el pago de la comisión de intermediación del corredor se efectúe en forma diferida en el tiempo, incluya pagos por concepto de gastos de inspección u otras actividades encargadas al corredor o esté sujeta al cumplimiento de determinadas condiciones, se deberá informar siempre el monto total de esta comisión, pudiendo incluirse en cada caso, una explicación en relación a la forma de pago y el desglose de la comisión en sus diversos componentes." Esta circular reemplaza y deroga circulares no 1457 , de 1999, y no 1759, de 2005. Disponible en: http://www.svs.cl/institucional/legislacion_normativa/normativa.php? mercado=G [fecha de visita: 19 de julio de 2014]. 
4. Costo total para el asegurado, incluyendo prima, impuestos y cualquier otro recargo;

5. Modalidades de pago de la prima;

6. Existencia, duración y forma de ejercicio del derecho a retracto del contratante o asegurado;

7. Derecho del asegurado a poner fin anticipado al contrato, en cualquier momento, comunicándolo al asegurador, salvo las excepciones legales.

8. Plazo máximo y forma de entrega de la póliza. El plazo de entrega no podrá exceder al indicado en el Código de Comercio.

Toda información deberá comunicarse de manera clara y comprensible ajustándose estrictamente a las condiciones de los seguros ofrecidos, evitando inducir a error o confusión para su aceptación y celebración. Se deberá señalar explícitamente que la oferta corresponde a un seguro y no a otro tipo de servicio o beneficio.

En caso que el cliente asegurable manifieste su interés por contratar el seguro ofrecido, deberá en forma previa a obtener su aceptación, y como medida de respaldo a su voluntad, confirmar sus datos personales, debiendo además el oferente entregarle sus datos de contacto.

En el punto V. se expresa un "Derecho de Retracto". Señalándose que: "En los contratos de seguro celebrados telefónicamente, el contratante o asegurado tendrá la facultad de retractarse dentro del plazo de diez días, contado desde que reciba la póliza, sin expresión de causa ni cargo alguno, teniendo el derecho a la devolución de la prima que hubiere pagado.

El derecho de retracto deberá informarse en forma destacada en la comunicación de envío de la póliza, sin perjuicio de lo dispuesto en el numeral 6 del Título III de la presente Circular.

El retracto del asegurado deberá comunicarse al asegurador o corredor de seguros que intermedie el seguro, por cualquier medio que permita la expresión fehaciente de voluntad, debiendo el asegurador o corredor conservar la comunicación correspondiente en forma íntegra y en un soporte duradero". Se debe registrar esta información en un soporte duradero, conforme al número VI. de la Circular 2128, ya que "Toda comercialización regulada en esta circular, deberá ser registrada íntegramente, debiéndose informar esta circunstancia al cliente" ${ }^{\prime 9}$.

59 "Se entenderá por soporte duradero el sistema técnico de transmisión, almacenamiento y resguardo de la información grabada de la comunicación, el que deberá encontrarse a disposición del asegurado y de este Servicio cuando este lo requiera.

En todo caso, el sistema de oferta y promoción de seguros que regula esta circular deberá comprender mecanismos de seguridad que resguarden la confidencialidad, integridad, no repudio y autenticación de la información registrada.

a) Confidencialidad: Garantía que la aceptación del seguro y la información proporcionada por el asegurable solo podrá ser utilizada por el oferente del servicio. 


\section{3) La SANCión de NULidad ante ClÁUsulas de FAlta de INFORMACIÓN. BASES PARA UNA FUTURA DISCUSIÓN}

Las secuelas del incumplimiento de esta carga de información, asesoría y asistencia para la aseguradora, debieran reconducirse por considerar como parte integrante de la cobertura aquello que no se explicite de manera clara y precisa y que pueda ser demostrado por el tomador-asegurado como parte de la cobertura. La imperatividad del artículo 542 del Código de Comercio, no debiera afectar al tomador-asegurado de seguros si la nulidad proviene de infracciones, errores y omisiones cometidos por la aseguradora y de los perjuicios causados a los asegurados-tomadores durante la contratación del seguro, porque ellos son de responsabilidad del asegurador, conforme al artículo $529 \mathrm{~N}^{\circ} 1$ del mismo Código de Comercio. En otras palabras, el asegurador, que es quien ejecuta el acto, y sabía o debía saber el vicio que invalidaba el mismo, como reza el artículo 1683 del Código Civil, no puede ejercer la acción de nulidad, aprovechándose de anular una relación jurídica en la que no desplegó adecuadamente su carga de información, asesoría y asistencia en desmedro del tomadorasegurado $^{60}$.

Por lo tanto, aquellas cláusulas en las que falta información sobre aspectos esenciales como la delimitación del riesgo asegurado, la estipulación de prima y la obligación condicional del asegurador de indemnizar,

b) Integridad: Garantía que la información no será alterada durante la transmisión y mantención.
c) No repudio: Garantía que el oferente del seguro no podrá negar su autoría y contenido.
d) Autenticación: Garantía que la persona a quien se ofrece el seguro corresponda efectivamente a
aquella a quien se ha querido contactar.
La entidad oferente del seguro será responsable por el permanente cumplimiento de todas las me-
didas de seguridad señaladas precedentemente, como de aquellas que correspondan para garanti-
zar la conservación de las bases de datos y grabaciones, y evitar su transferencia o divulgación a
personas no autorizadas. La Superintendencia podrá requerir en cualquier momento copia de la grabación telefónica y demás antecedentes relativos a los seguros comercializados telefónicamente". Todas las normas administrativas de SVS que se señalarán a continuación, están disponible en www.svs.cl (fecha de visita 19 de julio de 2014).

60 En esto, cabe tener presente, tal y como señala Ríos que: "el artículo 11 del Código Civil que indica que 'cuando la ley declara nulo algún acto, con el fin expreso o tácito de precaver un fraude, o de proveer a algún objeto de conveniencia pública o privada, no se dejará de aplicar la ley, aunque se pruebe que el acto que ella anula no ha sido fraudulento o contrario al fin de la ley'. Por su parte, el artículo 1469 de mismo Código establece que el contrato inválido, 'no dejará de serlo por las cláusulas que en ellos se introduzcan y en que se renuncie la acción de nulidad'. El contenido de las normas enunciadas, se ajusta, en nuestra opinión, a las características propias de la nulidad absoluta, sanción en la que aparecen como insoslayables los fundamentos de moralidad, orden público y gravedad del defecto del acto nulo. Consecuencia de ello, la voluntad del legislador es inalterable, debiendo esta primar por sobre toda voluntad negocial sustentada en los intereses particulares de los contratantes". Ríos Ossa, Roberto (2014) El deber precontractual de declaración de riesgo, Editorial Thomson Reuters La Ley, LegalPublishing, Santiago de Chile, p. 177. 
así como las prestaciones o aquellas en que las compañías aseguradoras se reserven la resolución del contrato por el mero acaecimiento del riesgo cubierto, debieran todas considerarse nulas para la compañía e interpretadas a favor del tomador-consumidor de las mismas en cuanto ceden en su beneficio. Como puede apreciarse, las cláusulas sobre información pueden situarse en cualquier parte del contrato. Por ello, si de certificados de cobertura provisorio o definitivo o propuesta se trata, cualquier obligación que provenga de la existencia y estipulaciones del contrato se podrán probar y hacer exigibles por todos los medios de prueba que contemplen las leyes, siempre que exista un principio de prueba por escrito que emane de cualquier documento que conste en télex, fax, mensajes de correo electrónico y, en general, cualquier sistema de transmisión y registro digital o electrónico de la palabra escrita o verbal, conforme al artículo 515 inciso segundo del Código de Comercio.

Sin embargo, se abre con la superposición legislativa entre la ley 20.555 y la ley 20.667 un problema difícil de dirimir y sobre el que de momento planteamos sus argumentos bases solamente. Lo dejaremos para otro trabajo por su complejidad y amplitud. Adelantamos simplemente que la arista problemática que deja abierta la dictación de ambas normas es la de dirimir si estamos ante situaciones de nulidad parcial o total de cláusulas por falta de información en la contratación de seguros o ante situaciones de nulidad absoluta del contrato. En otras palabras, se trata de zanjar si es posible conservar o preservar el contrato de seguro cuando sea superable el vicio de acuerdo a las normas del la LPC, específicamente el artículo 17 o, por el contrario y, de acuerdo al artículo 542 del Código de Comercio, asumir la ineficacia total del contrato cuando las cláusulas subsistentes determinen una situación no equitativa en la posición de las partes que no pueda ser subsanada. Ahondaremos en estos problemas del tráfico jurídico en otra oportunidad, si Dios quiere.

\section{CONCLUSIONES}

1. El certificado de cobertura provisorio o definitivo debe ser claro, preciso y ajustado a un lenguaje comprensible. Las consecuencias del incumplimiento de esta carga para la aseguradora, debieran reconducirse por considerar como parte integrante de la cobertura aquello que no se explicite de manera clara y precisa y que pueda ser demostrado, por medio de un principio de prueba por escrito, por el tomador-consumidor como parte de la cobertura. En efecto, la imperatividad del artículo 542 del Código de Comercio, no debiera afectar al tomador-consumidor de seguros si la nulidad proviene de infracciones, errores y omisiones cometidos por la aseguradora y de los perjuicios causados a los asegurados-consumidores durante 
la contratación del seguro, porque ellos son de responsabilidad del asegurador, conforme al artículo $529 \mathrm{~N}^{\circ} 1$ del mismo Código de Comercio. En otras palabras el asegurador, que es quien ejecuta el acto, a nuestro juicio sabía o debía saber el vicio que invalidaba el mismo, como reza el artículo 1683 del Código Civil, en consecuencia, no puede ejercer la acción de nulidad absoluta, aprovechándose de dejar sin efecto una relación jurídica en la que no desplegó adecuadamente su carga de información, asesoría y asistencia en desmedro del tomador-consumidor.

2. El derecho de información exigible actualmente en la contratación de seguros, excluidos los grandes riesgos, es todavía de más intensidad que aquel propio de la formación del consentimiento en el Código de Comercio. Ha habido un cambio de paradigma, ya que en lo que contratos de seguro se refiere, se ha pasado de un consentimiento libre y espontáneo, basado en la libertad contractual y la autonomía de la voluntad, a un auténtico consentimiento informado, que tiene su tutela precisamente en los deberes precontractuales de información. No podemos en este punto olvidar que los contratos de seguros, considerados estos como productos financieros, son contratos de protección e interpretación a favor del contratante más débil.

3. Los condicionados generales y particulares de los contratos de seguros, así como la costumbre mercantil han dejado de ser fuentes directas del contrato de seguro si atentan contra el tenor proasegurado de las normas del Código de Comercio, gracias a la consagración de la regla de la imperatividad del artículo 542 del mismo código. Esto significa que no podrá usarse por las compañías aseguradoras la imperatividad como una forma de desconocer coberturas fundadas en errores, imprecisiones u omisiones que han debido subsanarse por ellas mismas conforme al artículo 529 número 1 del CCOM.

4. Conforme a las últimas normas administrativas modificadas por la SVS, y que se han expuesto en este trabajo, toda información precontractual deberá comunicarse de manera clara y comprensible ajustándose estrictamente a las condiciones de los seguros ofrecidos, evitando inducir a error o confusión para su aceptación y celebración al tomador. Se ha consagrado administrativamente, de forma expresa, una carga de asesoría, información y asistencia al asegurado por parte de las aseguradoras y sus intermediarios.

5. Si en uso de las normas reglamentarias emanadas de la autoridad administrativa, en virtud del DFL 251, especialmente en su artículo $3^{\circ}$, la SVS desconoce, rebaja o limita las prerrogativas del tomador del seguro en cuanto a sus derechos consagradas en la ley, como es el caso del deber de información, estas disposiciones carecerán de valor por el orden público de protección a favor del contratante más débil 
expresado en el CCom y la LPC y en una correcta interpretación, deberán ser consideradas como nulas por aplicación del artículo 10 del Código Civil, debiendo siempre entenderse como válidas las estipulaciones contractuales que sean más beneficiosas para el asegurado o el beneficiario. De lo que se trata es de no causar un daño permanente al consumidor tomador de seguros y proteger sus derechos reconocidos en la ley, la nulidad es lo que debiera proteger.

\section{BIBLIOGRAFÍA CITADA}

- AAVV (2012) Todo Seguros, Coordinador D. Jorge Campos Moral, CISS grupo Wolters Kluwer, Madrid, p. 192.

- Arellano Iturriaga, Sergio (2013) La ley del seguro, Legal Publishing Thomson Reuters, Santiago, p. 26.

- Baraona, Jorge (2014) "La regulación contenida en la ley 19.496 sobre protección de los derechos de los consumidores y las reglas del código civil y comercial sobre contratos: un marco comparativo", Revista Chilena de Derecho, Vol. 41 N$^{\circ}$, pp. 381-408.

- Barrientos (2008) Daños y Deberes en las Tratativas Preliminares de un Contrato, LegalPublishing, Santiago de Chile, pp. 7-47.

- Bataller, Juan, Latorre, Nuria y Olavarría, Jesús (2007) Derecho de los Seguros Privados, Editorial Marcial Pons -Madrid- España, p.163.

- Contreras Strauch, Osvaldo (2014) Derecho de Seguros, Segunda Edición, Editorial LegalPublishing, Thomson Reuters, Santiago de Chile, p. 160, 760 pp

- Chagny, Muriel y Perdrix, Louis (2013) Droit des assurances, Segunda Edición, Editorial L.G.D.J., Paris, pp. 128 y ss.

- De la Maza, Iñigo (2010) Los Límites del Deber Precontractual de Información, Civitas, Madrid, pp. 59 y ss.; 413 pp.

- Diccionario Mapfre de seguros. Disponible en: http://www.mapfre. $\mathrm{com} /$ wdiccionario/terminos/vertermino.shtml?c/certificado-deseguro.htm, fecha de visita: 19 de julio de 2014.

- García Rubio y Otero (2010) La responsabilidad precontractual en el Derecho contractual europeo (Indret) p. 23. fecha de visita: 19 de julio de 2014.

- Heiss, Helmut (2012) "Proportionality in the New German Insurance Contract Act 2008”, Erasmus Law Review, Volume 5, Issue 2 (2012), p. 106.

- Illescas Rafael (2014) "Principios fundamentales del Contrato de Seguro", en Revista Española de Seguros, num. 157, 2014, eneromarzo, p.14. 
- Mayer-Schönberger, Viktot y Cukier, Keneth, (2013) Big Data: A Revolution That Will Transform How We Live, Work, and Think, Eamon Dolan/Houghton Mifflin, Nueva York.

- Morales Moreno, Antonio Manuel (1988) El error en los contratos, editorial Ceura, Madrid. p. 299.

- Rios Ossa, Roberto (2014) El deber precontractual de declaración de riesgo, Editorial Thomson Reuters La Ley, LegalPublishing, Santiago de Chile, pp. 11 y ss.

- Römer, Wolfgang (2009) "Die Reform des Versicherungsvertragsrechts" en Humboldt Forum Recht, 13/2009, pp. 3-6.

- Sánchez Calero, Fernando (2010) Ley de Contrato de Seguro, Aranzadi-Madrid, pp. 31 y 61.

- Stiglitz, Rubén (2008) Derecho de Seguros, Editorial La Ley Buenos Aires, Argentina) p.149.

- VAleri, Guiseppe (1950) Manuale di diritto commerciale. Tomo II, Firenze: Carlo Cya, p. 108.

- Veiga Copo, Abel (2014) Tratado del Contrato de Seguro, Tomo I, Tercera Edición, Editorial Thomson Reuters, Civitas, Madrid, p. 139.

- (2012) Los Principios de derecho europeo del contrato de seguros, Pontificia Universidad Javeriana de Colombia, Ibánez, Colección prospectivas del Derecho N², pp. 138-141.

\section{JURISPRUDENCIA CITADA}

- Corte de Apelaciones de Talca, de 2 de noviembre de 2011, rol 692-2011, "Espinoza Serrano, Marta/Compañia de Seguros Renta Nacional". Microjuris: MJCH_MJJ29914 | ROL: 692-11, MJJ29914. 